DIW BERLIN

Discussion Papers

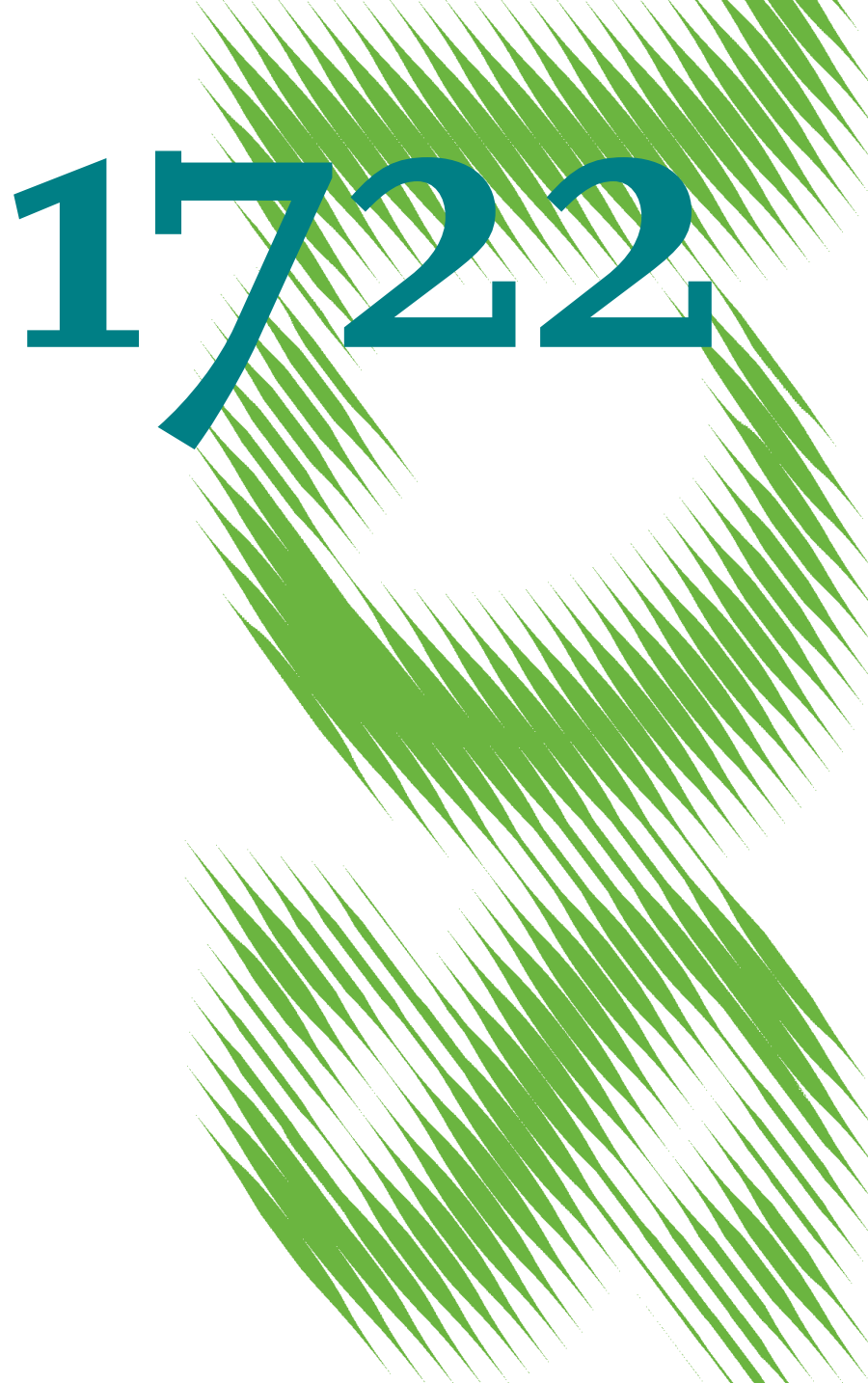

Nonlinear Intermediary Pricing in the Oil Futures Market 
Opinions expressed in this paper are those of the author(s) and do not necessarily reflect views of the institute.

IMPRESSUM

(C) DIW Berlin, 2018

DIW Berlin

German Institute for Economic Research

Mohrenstr. 58

10117 Berlin

Tel. +49 (30) $89789-0$

Fax +49 (30) $89789-200$

http://www.diw.de

ISSN electronic edition 1619-4535

Papers can be downloaded free of charge from the DIW Berlin website:

http://www.diw.de/discussionpapers

Discussion Papers of DIW Berlin are indexed in RePEc and SSRN:

http://ideas.repec.org/s/diw/diwwpp.html

http://www.ssrn.com/link/DIW-Berlin-German-Inst-Econ-Res.html 


\title{
Nonlinear Intermediary Pricing in the Oil Futures Market*
}

\author{
Daniel Bierbaumer ${ }^{\mathrm{a}} \quad$ Malte Rieth $^{\mathrm{b}} \quad$ Anton Velinov $^{\mathrm{c}}$
}

February 13, 2018

\begin{abstract}
We study the state-dependent trading behavior of financial intermediaries in the oil futures market, using structural vector autoregressions with Markov switching in heteroskedasticity. We decompose changes in futures price volatility into changes in the slopes of traders' demand curves and in the variability of their demand shocks. We find that the downward-sloping demand curve of intermediaries steepens significantly during turbulent times. Moreover, the variance of intermediaries' own demand shocks doubles during these episodes. These findings suggest that the futures pricing of intermediaries is nonlinear and increases the hedging costs of producers and processors of oil when volatility is high.
\end{abstract}

JEL Classification: C32, G12, G21, Q02.

Keywords: Commodities, Structural VAR, Financial Intermediaries, State-dependency, Asset Pricing, Markov Switching.

\footnotetext{
* We are thankful to Christiane Baumeister, Kahild ElFayoumi, Marcel Fratzscher, Lutz Kilian, Gary Koop, Philipp König, Helmut Lütkepohl, Gert Peersman, Barbara Rossi, Simon Rother, Gregory Thwaites as well as participants of the Empirical Macroeconomics Workshop at Freie Universität Berlin 2016, the Nordic Econometric Meeting 2017 Tartu, the Annual Meeting of the Nationalökonomische Gesellschaft Österreichs 2017 Vienna, the Energy and Commodity Finance Conference 2017 Oxford, the Conference of the International Association for Applied Econometrics 2017 Sapporo, the Annual Meeting of the Verein für Socialpolitik 2017 Vienna, the Quantitative Economics Seminar of University Hamburg, the International Conference on Computational and Financial Econometrics London, and DIW research seminars for helpful comments and suggestions.

${ }^{\text {a }}$ Humboldt University of Berlin, University of Potsdam and German Institute for Economic Research; e-mail: dbierbaumer@diw.de

b German Institute for Economic Research; e-mail: mrieth@diw.de

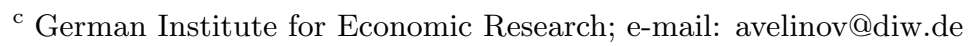





\section{Introduction}

Traditional theories of asset pricing assign no role to financial intermediaries and view them as a veil without influence on the functioning of financial markets. This conjecture has been questioned. Modern theories state that intermediaries, broadly defined as entities which channel funds between different parties, affect asset prices due to several frictions (Shleifer and Vishny, 1997, Kyle and Xiong, 2001, Fostel and Geanakoplos, 2008). Following the global financial crisis, Brunnermeier and Pedersen (2009) and He and Krishnamurthy (2013) show theoretically how asset price dynamics may change during crises in markets where intermediaries are the marginal investors. Under financial stress, intermediaries' funding constraints can become binding and their risk-bearing capacity may shrink. Such occasionally binding constraints lay the foundation for nonlinearities in the performance of asset markets and can give rise to liquidity dry-ups and volatility spikes.

Based on these theoretical insights, several empirical papers study the relation between asset prices and a variety of measures of intermediaries' financial health. Adrian et al. (2014) document a relationship between the marginal value of intermediaries' wealth and asset returns. He et al. (2016) find that intermediaries act as marginal investors in many asset markets. Focusing on commodity markets, Acharya et al. (2013) show that the severity of intermediaries' capital constraints affects futures risk premia, and Etula (2013) highlights the relevance of the riskbearing capacity of securities broker-dealers for futures risk premia.

These empirical findings support the theoretical arguments that the risk and trading constraints of financial institutions are time-varying and change through volatility regimes. They further suggest that such nonlinearities are key to understand commodity futures markets and, given an arbitrage relation, potentially also spot prices. What is missing in the literature, however, is an analysis of the state-dependent trading behavior of financial intermediaries and the associated implications for price dynamics. We aim to fill this gap by building a Markov switching in heteroskedasticity structural vector autoregressive (MSH-SVAR) model for the oil futures market, using weekly position data from the U.S. Commodity Futures Trading Commission (CFTC) for the period 2006-2016. We focus on oil as the large exposure of banks to the oil sector has raised concerns about financial stability (Domanski et al., 2015), but our approach can be applied to other commodities.

We use a stylized conceptual framework following Cheng et al. (2015). It describes the trading behavior of different trader groups in terms of simple net long demand curves depending on the contemporaneous futures price and a group-specific demand shock. The framework provides sufficient restrictions for just-identification of the structural empirical model. The main identifying assumption is that traders do not directly respond to position changes of other trader groups. This assumption is consistent with a publication lag of the CFTC data and the electronic trading at the New York Mercantile Exchange to which the data refer, making aggregate position changes of other trader groups contemporaneously unobservable. We consider two states of the world: tranquil and volatile periods. The endogenous determination of these states is at the core of the analysis. The Markov switching framework allows us to be agnostic and gives full voice to the data (Hamilton, 1994), thereby reducing the risk of misspecification of the transition points, variable(s), or functions. Since the structural model is just-identified for 
each state, we can let both the impact effects and the volatility of the structural shocks switch across states. This facilitates a decomposition of changes in futures price volatility into changes in the slopes of traders' demand curves and in the volatility of their demand shocks.

Our paper contributes to the literature along several dimensions. The results show that the trading behavior of financial intermediaries changes significantly across states. First, the demand curve of intermediaries steepens significantly when switching from the tranquil to the turbulent state. The lower price elasticity implies that they are less willing or able to absorb trades of other groups. This increases the price effect of futures demand shocks by two thirds according to our estimates. Second, the variance of intermediaries' own demand shocks doubles during these episodes, further raising price volatility. Both findings are consistent with the theoretically predicted nonlinearities in Brunnermeier and Pedersen (2009) and He and Krishnamurthy (2013).

Our study also relates to a long-standing literature on the determination of commodity futures prices, and their relation to spot prices. ${ }^{1}$ Recently, there has been much interest in the role of financial institutions in these markets and whether the increased presence of financial investors has changed the functioning of commodity markets (Fattouh et al., 2013, Cheng and Xiong, 2014). Our analysis focuses on the role of financial intermediaries in the price formation process in the oil futures market. We show that their trading behavior is state-dependent and that this increases the hedging costs of producers and processors of oil in high volatility regimes.

The paper builds on a literature on structural time-series models with heteroskedasticity (Rigobon, 2003). We combine the type of Markov switching models following Herwartz and Lütkepohl (2014) with the framework of Bacchiocchi and Fanelli (2015). The first model type determines regime switches endogenously, but allows only for changes in the volatility of the structural shocks across regimes. The second class allows for changes in both the contemporaneous effects and the volatility of the structural shocks, but defines the regimes exogenously based on prior information. Our model contains both desirable features: an endogenous regime determination, and changes in the impacts and in volatility. This is crucial for our analysis as it allows, first, endogenously estimating when significant changes in volatility occur and, second, decomposing them into changes in the slopes of demand curves and into changes in the volatility of demand shocks. Another important difference to the aforementioned models is that we do not use the heteroskedasticity in the data for identification. The latter is achieved through economic reasoning, implying that our identified structural shocks have the simple economic interpretation as net long demand shocks of the trader groups included in the model.

Our results are robust to a large number of sensitivity tests. We also compare them with estimates from popular alternative classes of nonlinear models - threshold and smooth transition models - based on a single transition variable (Kilian and Lütkepohl, 2017, Ch. 18). These models yield similar conclusions regarding the state-dependent trading behavior of financial intermediaries. Furthermore, they show that the choice of the transition variable plays an important role in determining the model outcomes, that none of the exogenously determined states captures both the general financial market turmoil periods and the oil-market-specific events that the Markov switching model detects, and that the structural parameters are less

\footnotetext{
${ }^{1}$ See Garbade and Silber (1983), Hirshleifer (1990), Kilian and Murphy (2014), Hamilton and Wu (2015), Henderson et al. (2015), Sockin and Xiong (2015), Knittel and Pindyck (2016).
} 
precisely estimated across states. Finally, we investigate whether combinations of variables can capture the Markov switching regimes. We relate the smoothed probability of the high volatility state to model-external variables through logit regressions. They show that higher Baa-Aaa corporate spreads and lower U.S. Treasury yields are the best indicators of turbulent times, consistent with risk premia and risk-free rates being important factors for the futures basis and hence for futures price dynamics (Acharya et al., 2013, Szymanowska et al., 2014).

The remainder of the paper is structured as follows. The next section discusses the literature on intermediary asset pricing, presents a simple conceptual framework and some testable implications. It further outlines the empirical methodology and describes the data. Section 3 contains the main results, while Section 4 compares them to other modeling approaches and provides further evidence on the characteristics of the high volatility state. This section also contains an extensive sensitivity analysis. The last section concludes.

\section{Conceptual Framework, Empirical Model and Data}

In this section, we first summarize the literature on intermediary asset pricing. Using the findings in the literature, we present a conceptual framework and derive two testable implications for the trading behavior of intermediaries in the oil futures market. The section ends with a description of the data.

\subsection{Conceptual Framework}

Traditional theories of asset pricing regard financial intermediaries as a veil without influence on the performance of asset markets. Intermediaries act according to their clients' preferences, making a representative household the marginal investor. This neglect of the intermediary sector has been questioned by numerous studies showing that intermediaries face a variety of constraints, such as limits to arbitrage, due to which they influence the functioning of asset markets (Kyle and Xiong, 2001, Fostel and Geanakoplos, 2008). In an influential paper Brunnermeier and Pedersen (2009) show the interdependence between the ability of intermediaries to raise capital and market liquidity. When funding liquidity is scarce, intermediaries are reluctant to open new positions, market liquidity is lower, and volatility is higher. He and Krishnamurthy (2013) study the asymmetric effects of intermediary capital on risk premia. When capital is abundant, intermediaries are able to offset losses such that there are only limited effects on risk premia. When capital is scarce, however, losses in the intermediary sector can be associated with higher and more volatile risk premia.

The subsequent empirical literature has studied the relation between intermediaries' financial health, using a variety of approximations of this unobservable variable, and asset prices. Adrian et al. (2014) investigate the relation between a stochastic discount factor based on the leverage of security broker-dealers and asset returns. He et al. (2016) use capital ratios of intermediaries and provide evidence that intermediaries are the marginal investors in many asset markets and thus key to understanding price formation. Focusing on commodity markets, Acharya et al. (2013) show that the futures risk premium and hence producers' hedging costs are increasing in the severity of intermediaries' capital constraints, measured by their assets relative to households' 
assets. Etula (2013) uses the leverage of securities broker-dealers, who serve as counterparties to hedgers, to build a risk aversion index and finds that it is a determinant of risk premia in commodity futures markets. Finally, Cheng et al. (2015) approximate the risk absorption capacity of financial traders in commodity futures markets with the VIX and document a risk transfer from those traders to hedgers during periods of high volatility.

These contributions suggest that when volatility is high (i) intermediaries are more reluctant to take on new positions, and (ii) their exposure to idiosyncratic balance sheet shocks increases. To map these considerations into testable implications, we formulate a stylized model of the oil futures market, following Cheng et al. (2015). The framework describes the trading behavior of all market participants, who are assumed to be atomistic price takers. We distinguish between three groups of traders: hedgers $(H)$, financial intermediaries $(F)$, and others $(O)$. Hedgers are producers, processors, or large consumers of oil, who want to hedge physical oil price risk of commercial businesses. For the second group, we primarily think of it as large banks that either trade on behalf of clients without direct access to the futures market or on their own behalf. The third group contains all remaining traders and is mainly comprised of specialized commodity trading advisors, commodity pool operators, and traders who cannot be clearly classified in any other category. The demand curves of the three trader groups are

$$
\begin{aligned}
& \Delta y^{H}=-a^{H}(S) \Delta P+\sqrt{\lambda^{H}(S)} \nu^{H} \\
& \Delta y^{F}=-a^{F}(S) \Delta P+\sqrt{\lambda^{F}(S)} \nu^{F} \\
& \Delta y^{O}=-a^{O}(S) \Delta P+\sqrt{\lambda^{O}(S)} \nu^{O},
\end{aligned}
$$

where $\Delta y^{i}$ denotes the change in the net long oil futures position of trader group $i=H, F, O$. $\Delta P$ is the change in the oil futures price. The coefficients $a^{i}(S)$ determine the slope of the respective demand curve and thus measure the price elasticity of each group. They reflect the capacity or willingness to absorb trades of other groups. Illiquidity might arise if there are limits to arbitrage which deter risk averse arbitrageurs from taking the counter-side. Shleifer and Summers (1990) and Shleifer and Vishny (1997), for example, show that large position changes can influence prices through an effect on the order book if the instantaneous supply of counterparty orders is low. Regarding financial intermediaries, a smaller value of $a^{F}$ implies that they absorb a smaller part of the desired demand shift of producers and processors or, equivalently, provide less liquidity, and that the price impact will be larger.

Each demand curve further features a random shock $\nu^{i}$ which causes the respective trader group to adjust its net long position due to own reasons. For financial intermediaries the causes can be manifold: portfolio diversification, risk management, speculative motives based on private signals, or long hedging of short exposure vis-à-vis clients. The $\lambda^{i}(S)$ 's measure the variances of the shocks and are allowed to differ across groups. One can interpret these coefficients as the exposure of each trader group to its idiosyncratic shocks. For example, if we think of $\nu^{F}$ as a shock hitting the balance sheets of intermediaries, then a larger $\lambda^{F}$ suggests a greater exposure to this shock. Although being highly stylized, the simple demand functions thus capture two main trading motives of financial institutions in commodity futures markets: liquidity provision to other traders and trading for own purposes. The usual market clearing 
condition, $\Delta y^{H}+\Delta y^{F}+\Delta y^{O}=0$, closes the model and ensures that the price is jointly determined by all trader groups in equilibirum.

We distinguish in an ad-hoc form between two different states $S=1,2$ of the world. Without loss of generality, we think of state 1 as tranquil periods and of state 2 as volatile times. The latter can be either episodes of general financial market turmoil that spill over to the oil futures market through balance sheets of intermediaries or drastic oil market developments that directly affect intermediaries in the oil futures market. The central feature of the model is that the $a^{i}(S)$ and $\lambda^{i}(S)$ coefficients are allowed to differ between regimes. Hence, both the ability of traders to absorb other traders' shocks as well as the variance of own shocks can change between states. Using the market clearing condition and writing the system in matrix notation gives

$$
\left(\begin{array}{rrr}
1 & 0 & a^{H}(S) \\
0 & 1 & a^{F}(S) \\
-1 & -1 & a^{O}(S)
\end{array}\right)\left(\begin{array}{c}
\Delta y^{H} \\
\Delta y^{O} \\
\Delta P
\end{array}\right)=\left(\begin{array}{c}
\sqrt{\lambda^{H}(S)} \nu^{H} \\
\sqrt{\lambda^{F}(S)} \nu^{F} \\
\sqrt{\lambda^{O}(S)} \nu^{O}
\end{array}\right) .
$$

This expression is the basis for the identification of our structural empirical model. It illustrates our main identifying restrictions which are reflected in the zero elements on the LHS of (1). We assume that no trader group responds directly to the position change of any other group. This assumption is consistent with the publication lag of the CFTC data that we use and the market to which they refer. The positions correspond to each Tuesday end-of-day at the electronic trading platform of the New York Mercantile Exchange. Here, aggregated orders of the other investors are not observable. But the CFTC reports are released only the following Friday, implying that traders cannot contemporaneously observe and thus directly respond to aggregated position changes of other groups. They do so, of course, indirectly through prices.

Given the theoretical literature discussed above and to focus the empirical analysis, we now postulate the following two hypotheses about the changes in the coefficients across states:

Hypothesis 1 The downward-sloping demand curve of financial intermediaries steepens during turbulent times: $a^{F}(2)<a^{F}(1)$.

Hypothesis 2 The volatility of intermediaries' demand shifts increases during turbulent times: $\lambda^{F}(2)>\lambda^{F}(1)$.

The alternative hypotheses are that there are no significant changes across regimes, implying that there is no clear difference in the way financial intermediaries trade in tranquil versus turbulent times, or that the changes in parameters are significant but with the opposite sign. Finally, unlike Cheng et al. (2015), our framework does not contain a common shock which simultaneously affects all trader groups (potentially to differing degrees). This reduces the computational complexity of the estimation. Instead, we deal which such shocks by including a number of exogenous control variables in the baseline empirical model and by conducting an extensive sensitivity analysis adding further controls. 


\subsection{The MSH-SVAR Model}

We now describe the general $M$ state, $p$ lag reduced form Markov switching in heteroskedasticity structural vector autoregressive (MSH-SVAR) model:

$$
y_{t}=c+\Gamma_{1} y_{t-1}+\cdots+\Gamma_{p} y_{t-p}+\Psi_{0} x_{t}+\Psi_{1} x_{t-1}+\cdots+\Psi_{n} x_{t-n}+u_{t}
$$

where in our case $y_{t}=\left[\Delta y_{t}^{H}, \Delta y_{t}^{F}, \Delta P_{t}\right]^{\prime}$ is the vector of endogenous variables with $\Delta y_{t}^{H}$ and $\Delta y_{t}^{F}$ the change in the net long futures position of hedgers and financial intermediaries, respectively, and $\Delta P_{t}$ the oil futures return. Further, $x_{t}$ is a vector of $W$ exogenous variables discussed below, $\Gamma_{i}$ and $\Psi_{j}$ are parameter matrices with $i=1, \ldots, p$ and $j=1, \ldots, n$, where $n$ does not necessarily equal $p$, and $c$ is a vector of constants. Finally, $u_{t}$ is a vector of reduced form error terms with $\mathbb{E}\left[u_{t}\right]=0$ and $\mathbb{E}\left[u_{t} u_{t}^{\prime}\right]=\Sigma_{u}\left(S_{t}\right)$. For estimation purposes, we assume that $u_{t}$ is normally and independently distributed conditional on a given state:

$$
u_{t} \mid S_{t} \sim \operatorname{NID}\left(0, \Sigma_{u}\left(S_{t}\right)\right)
$$

Here, $S_{t}$ is a first order discrete valued Markov process that can take on $M$ different values, $S_{t}=1, \ldots, M$, with transition probabilities given by $p_{k l}=P\left(S_{t}=l \mid S_{t-1}=k\right), k, l=1, \ldots, M$. Although the model is linear in a given state, it is nonlinear as a whole.

Using the conceptual model in (1), we write the structural empirical model as

$$
\underbrace{\left[\begin{array}{rrr}
1 & 0 & a^{H}\left(S_{t}\right) \\
0 & 1 & a^{F}\left(S_{t}\right) \\
-1 & -1 & a^{O}\left(S_{t}\right)
\end{array}\right]}_{\equiv A\left(S_{t}\right)} \underbrace{\left[\begin{array}{c}
\Delta y_{t}^{H} \\
\Delta y_{t}^{F} \\
\Delta P
\end{array}\right]}_{=y_{t}}=\left[\begin{array}{c}
\epsilon_{t}^{H} \\
\epsilon_{t}^{F} \\
\epsilon_{t}^{O}
\end{array}\right],
$$

where $\epsilon_{t}=\left[\begin{array}{lll}\epsilon_{t}^{H} & \epsilon_{t}^{F} & \epsilon_{t}^{O}\end{array}\right]^{\prime}$ is a vector of structural shocks whose standard deviations correspond to $\sqrt{\lambda^{i}}$ in the conceptual model, and where we have neglected constants, lags and exogenous variables for illustration. ${ }^{2}$ This leads to the following relationship between the reduced form errors and the structural shocks: $u_{t}=A\left(S_{t}\right)^{-1} \epsilon_{t}$, where $A\left(S_{t}\right)^{-1}$ is a matrix of state-dependent instantaneous effects.

It is important that despite the zeros in $A\left(S_{t}\right)$ all variables are allowed to react contemporaneously to all shocks since

$$
A^{-1}\left(S_{t}\right)=\left[\begin{array}{ccc}
\frac{a^{F}\left(S_{t}\right)+a^{O}\left(S_{t}\right)}{\tilde{a}\left(S_{t}\right)} & -\frac{a^{H}\left(S_{t}\right)}{\tilde{a}\left(S_{t}\right)} & -\frac{a^{H}\left(S_{t}\right)}{\tilde{a}\left(S_{t}\right)} \\
-\frac{a^{F}\left(S_{t}\right)}{\tilde{a}\left(S_{t}\right)} & \frac{a^{H}\left(S_{t}\right)+a^{O}\left(S_{t}\right)}{\tilde{a}\left(S_{t}\right)} & -\frac{a^{F}\left(S_{t}\right)}{\tilde{a}\left(S_{t}\right)} \\
\frac{1}{\tilde{a}\left(S_{t}\right)} & \frac{1}{\tilde{a}\left(S_{t}\right)} & \frac{1}{\tilde{a}\left(S_{t}\right)}
\end{array}\right],
$$

where $\tilde{a}\left(S_{t}\right)=a^{H}\left(S_{t}\right)+a^{F}\left(S_{t}\right)+a^{O}\left(S_{t}\right)$. This is a central feature of the model and a main building block of the empirical plausibility of our identifying assumptions as traders respond to each other through prices in nearly continuous time. Any zero restrictions on $A^{-1}\left(S_{t}\right)$ would thus be difficult to justify. The specific structure of $A^{-1}\left(S_{t}\right)$ follows from the restrictions placed

\footnotetext{
${ }^{2}$ Implicitly this means that $\nu^{i} \sim(0,1)$ and that $\epsilon^{i} \equiv \sqrt{\lambda^{i}(S)} \nu^{i} \sim\left(0, \lambda^{i}(S)\right)$.
} 
on $A\left(S_{t}\right)$ and reveals that a change of $a^{F}\left(S_{t}\right)$ across states affects the response of all variables to all shocks as it enters the denominator of all elements in $A^{-1}\left(S_{t}\right)$.

In order to allow for state-dependence of the instantaneous effects we model $A\left(S_{t}\right)$ as

$$
A\left(S_{t}\right)=\bar{A}+\mathcal{A}\left(S_{t}\right), \quad S_{t}=1, \ldots, M
$$

where $\bar{A}$ consists of the state-invariant part and $\mathcal{A}\left(S_{t}\right)$ is the state-dependent part of the matrix. For simplicity, we set $\mathcal{A}(1)=0$. To summarize, the definitions are

$$
A\left(S_{t}\right)=\left[\begin{array}{rrr}
1 & 0 & a^{H}\left(S_{t}\right) \\
0 & 1 & a^{F}\left(S_{t}\right) \\
-1 & -1 & a^{O}\left(S_{t}\right)
\end{array}\right], \quad \bar{A}=\left[\begin{array}{rcc}
1 & 0 & \bar{a}^{H} \\
0 & 1 & \bar{a}^{F} \\
-1 & -1 & \bar{a}^{O}
\end{array}\right], \quad \mathcal{A}\left(S_{t}\right)=\left[\begin{array}{lll}
0 & 0 & \alpha^{H}\left(S_{t}\right) \\
0 & 0 & \alpha^{F}\left(S_{t}\right) \\
0 & 0 & \alpha^{O}\left(S_{t}\right)
\end{array}\right] .
$$

Further, we assume that the structural errors have a non-identity diagonal covariance matrix: $E\left[\epsilon_{t} \epsilon_{t}^{\prime}\right]=\Lambda\left(S_{t}\right)$ (naturally $E\left[\epsilon_{t}\right]=0$ ). We allow this matrix to be state-dependent in an analogous fashion as above

$$
\Lambda\left(S_{t}\right)=\bar{\Lambda}+\Lambda\left(S_{t}\right), \quad S_{t}=1, \ldots, M,
$$

where each matrix is diagonal. A typical element of $\Lambda\left(S_{t}\right)$ is $\lambda^{i}\left(S_{t}\right)=\bar{\lambda}^{i}+\ell^{i}\left(S_{t}\right)$, where $\bar{\lambda}^{i}$ and $\ell^{i}\left(S_{t}\right)$ are the respective elements of $\bar{\Lambda}$ and $\Lambda\left(S_{t}\right)$. Again, for simplicity, we set $\Lambda(1)=0$. The covariance matrix of the reduced form errors can then be written as

$$
\Sigma_{u}\left(S_{t}\right)=A\left(S_{t}\right)^{-1} \Lambda\left(S_{t}\right)\left(A\left(S_{t}\right)^{-1}\right)^{\prime}
$$

The system contains six structural parameters per state. These can be directly mapped to the six unique reduced form parameters through (7). The model is thus just-identified for any $M$; due to restrictions based on economic reasoning, without relying on changes in volatility. This approach uses a combination of established approaches found in the literature. For instance, the decomposition in (7) is used by Lanne et al. (2010), Herwartz and Lütkepohl (2014) and others. In addition, analogous decompositions as in (4) and (6) can be found in Bacchiocchi and Fanelli (2015). While our approach does make use of existing techniques, unlike in the literature, we do not assume an identity covariance matrix for the structural shocks in the first state, that is, $\Lambda(1) \neq I$, and we use, in the terminology of Lütkepohl (2005, Ch. 9), an $A$-model for identification instead of a $B$-model, which is employed in the aforementioned papers.

Finally, the Markov switching model differs from models with exogenously determined regimes, such as threshold and smooth transition structural time-series models in that it treats any potential transition variable(s) as latent. This allows the researcher to be more agnostic on the state determination. Section 4.1 compares our results with results from such models.

\subsection{Estimation and Bootstrap Procedure}

The parameters in (2) are estimated by means of the expectation maximization (EM) algorithm of Hamilton (1994, Ch. 22), which was extended to multivariate processes by Krolzig (1997). Crucial for the analysis is to incorporate the regime-switching nature of the covariance matrix described in (4) and (6), given the restrictions in (5). Note that the latter do not contain any 
sign restrictions on the coefficients $a^{i}(S)$. Following Podstawski and Velinov (2016), we use the following concentrated out log likelihood function in the maximization step of the EM algorithm:

$$
\begin{aligned}
l(\bar{A}, \mathcal{A}(2), \ldots, \mathcal{A}(M), \bar{\Lambda}, \Lambda(2), \ldots, \Lambda(M))= & \frac{1}{2} \sum_{m=1}^{M}\left[\widehat{T}_{m} \log \left(\operatorname{det}\left(\Sigma_{u}(m)\right)\right)\right. \\
& \left.+\operatorname{tr}\left(\left(\Sigma_{u}(m)\right)^{-1} \sum_{t=1}^{T} \widehat{\xi}_{m t \mid T} \widehat{u}_{t} \widehat{u}_{t}^{\prime}\right)\right],
\end{aligned}
$$

where $\Sigma_{u}(m)$ is defined as in (7). Further, $\xi_{m t \mid T}, m=1, \ldots, M, t=1, \ldots, T$ are the model smoothed probabilities, $T_{m}=\sum_{t=1}^{T} \xi_{m t \mid T}$, and the hat symbol denotes estimated parameters obtained from the previous iteration.

Once the EM algorithm has converged, we obtain standard errors of the point estimates of the parameters through the inverse of the negative Hessian matrix evaluated at the optimum. We use these standard errors as a first statistic to determine whether the estimated parameters change significantly across states. As a second statistic, we use Likelihood Ratio tests, where we restrict the main parameters of interest to be time-invariant. As a third statistic, we compute bootstrapped impulse responses. Given the heteroskedasticity, classical residual bootstrapping may be problematic in generating reliable confidence intervals. Any re-sampling scheme needs to preserve the second order characteristics of the data. We therefore use a fixed design wild bootstrap with $u_{t}^{\star}=\varphi_{t} \widehat{u}_{t}$, where $\varphi_{t}$ is a random variable independent of $y_{t}$ following a Rademacher distribution. $\varphi_{t}$ is either 1 or -1 with probability 0.5 . This is a commonly used technique for these types of models (Herwartz and Lütkepohl, 2014, Podstawski and Velinov, 2016).

\subsection{Data}

We use data of the Disaggregated Commitments of Traders (DCOT) Report of the U.S. Commodity Futures Trading Commission (CFTC). The data are weekly and start from 13 June 2006 to May 24, 2016, thereby containing 520 observations. Due to data availability, we could not start our sample earlier. However, given the weekly frequency of the data, we have a good amount of observations to estimate our parameters precisely. We calculate the net long position of the trader groups denoted as "Producer/Merchant/Processor/User" and "Swap Dealer" in light sweet crude oil traded at the New York Mercantile Exchange (NYMEX) to approximate net long demand of hedgers and financial intermediaries, respectively. Given the computational complexity of the empirical model we focus on these two trader groups, as they have relatively well defined business models within classifications, and lump the remaining groups in the price equation. In Section 4.3, we show that the main results are insensitive to adding another trader group to the model. Regarding the oil futures price, we employ the next-to-maturity futures settlement price of light crude oil at NYMEX. All three endogenous variables enter the model in standardized first differences, or log differences in case of prices.

According to the definition of the CFTC, a swap dealer is "[a]n entity that deals primarily in swaps for a commodity and uses the futures markets to manage or hedge the risk associated with those swaps transactions" (CFTC, 2017a). The vast majority of them are major global banks and the remaining traders in this group are other banks and financial intermediaries (CFTC, 
2017b). Heumesser and Staritz (2013) document that the four largest globally active banks in this category held around $70 \%$ of swap positions in commodity futures markets in 2008, namely, Goldman Sachs, Morgan Stanley, JP Morgan, and Barclays Bank. In 2012 the group was made up of Bank of America, JP Morgan, Goldman Sachs, and Citibank. Other banks with big swap positions include Merril Lynch, Deutsche Bank, HSBC, Credit Suisse, Rabobank, and UBS.

One caveat of the CFTC data are potential misclassifications of traders and hence reporting errors. First, financial intermediaries have incentives to be classified as hedgers since this entitles them to preferential treatments. Hedgers are exempted from position limits and face lower margins requirements, translating into less capital needed for maintaining open positions. Second, the data refer to total end-of-day positions of traders, meaning that positions are aggregated across trades due to different business reasons. This aggregation complicates an interpretation of position changes. Third, the CTFC itself changes the classification of traders from time to time, for example following alterations in the way traders participate in the futures market. Overall, misclassifications cannot be fully excluded. But the bias of these reporting errors is likely to imply that some financial traders are erroneously classified as hedgers and our results might then actually represent a lower bound of the influence of intermediaries on futures prices.

Finally, we augment the model with a number of contemporaneous exogenous variables to control for common factors that potentially affect positions of all trader groups simultaneously. We add the number of initial jobless claims to capture the state of the real economy and the balance sheet of the Fed to account for nominal developments. Both variables are available at the weekly frequency. Moreover, we include the surprise component in news releases of 30 U.S. macroeconomic indicators to account for public information approaching the market. In Section 4.3 we show that the results are insensitive to the inclusion of a large number of further exogenous variables. Appendix A contains a complete description of the data used in the analysis.

\section{Results}

We start by showing statistical evidence supporting the choice of a regime-switching model, followed by a brief presentation of the endogenously determined states. We then discuss the model's main implications in terms of estimated structural parameters. Additionally, we report bootstrapped impulse responses and forecast error variance decompositions.

\subsection{Model Selection}

Table 1 shows two types of specification statistics for the Markov switching model. ${ }^{3}$ The left panel shows lag selection criteria. We follow the literature and select the lag order of the endogenous variables in the MSH-VAR model based on a linear VAR model. All three information criteria point to one lag. This also seems plausible from an economic point of view, given that financial markets react immediately and adjust quickly to new information, and since our data are of weekly frequency. We use the same lag length for the exogenous variables.

\footnotetext{
${ }^{3}$ In the Markov switching model only the covariance matrix is switching between the sates, the autoregressive coefficients and the intercept are state-independent. In Section 4.3, we estimate a model with changing intercept.
} 
The right panel shows that a MSH-VAR model is clearly preferred over a standard linear VAR according to the log-likelihoods and information criteria. The latter have been shown to work well to judge the performance of MS models (Psaradakis and Spagnolo, 2006), whereas standard tests are problematic for determining the number of states (Hansen, 1992). The choice of two states is motivated by theoretical reasoning (see Section 2). This number suffices to test our two hypotheses. Estimation of a two-state model is also less cumbersome and leads to more stable and precise estimates, given that a potential third state contains only a limited number of observations. Nevertheless, we consider a three state model in the robustness analysis.

Table 1: Model Specification Tests

\begin{tabular}{cccc}
\hline & AIC & SC & HQ \\
\hline $\operatorname{Lag}(\mathrm{s})$ & 1 & 1 & 1 \\
\hline
\end{tabular}

Note: Lag selection based on Akaike information criterion, Schwarz criterion, and Hannan-Quinn criterion.

\begin{tabular}{lccc}
\hline Model & LogLike & AIC & SC \\
\hline reduced form linear VAR & -2069.4 & 4354.7 & 4813.7 \\
reduced form MSH-VAR, 2 states & -1957.2 & 4158.3 & 4676.8 \\
\hline
\end{tabular}

Note: Model fit comparison of a linear VAR and a two-state MSHVAR with lag order $n=p=1$ based on the log-likelihood, Akaike information criterion, and Schwarz criterion.

\subsection{Smoothed State Probabilities}

One main feature of the Markov switching model is the endogenous determination of the two states based on changes in the reduced form covariance matrix. For the labeling of the states we look at the diagonal elements of the reduced form covariance matrices:

$$
\Sigma_{u}(1)=\left(\begin{array}{rrr}
0.58 & \cdot & \cdot \\
0.00 & 0.74 & \cdot \\
-0.11 & -0.33 & 0.31
\end{array}\right) \quad \Sigma_{u}(2)=\left(\begin{array}{rrr}
1.34 & \cdot & \cdot \\
-0.29 & 0.78 & \cdot \\
-0.23 & 0.05 & 1.58
\end{array}\right)
$$

Equation (8) shows that there is a low-volatility regime, state 1, with relatively small variances, and a high-volatility regime, state 2, with larger variances. Especially the variance of the oil futures return increases strongly from 0.31 to 1.58 in state 2 . The variance of net long positions of hedgers also more than doubles from 0.58 to 1.34 . In contrast, the variance of net long positions of financial intermediaries increases only mildly from 0.74 to 0.78 . Through the lens of the conceptual model, this modest change is likely reflecting two offsetting forces. On the one hand, a steeper demand curve of intermediaries (Hypothesis 1) means that they are less priceelastic and implies that a given order of other market participants induces a smaller change in intermediaries' positions and a larger price increase. On the other hand, a rise in the volatility of intermediaries' own demand shocks (Hypothesis 2) is tantamount to a rise in the variance of their positions. Together, we thus observe a small increase in the variance of intermediaries' positions and a large increase in the variance of the price in state 2 . In the following we refer to state 1 as the "tranquil state" and to state 2 as the "turbulent state."

Figure 1 plots the smoothed probability of state 2 . The dashed lines display a suggested selection of events that are likely to have had an effect on intermediaries in the oil futures market and potentially help rationalize the switches in the states. The switches occur both around events directly related to the oil futures market and during periods of more general 
Figure 1: Smoothed Probabilities of State 2

\section{State 2}

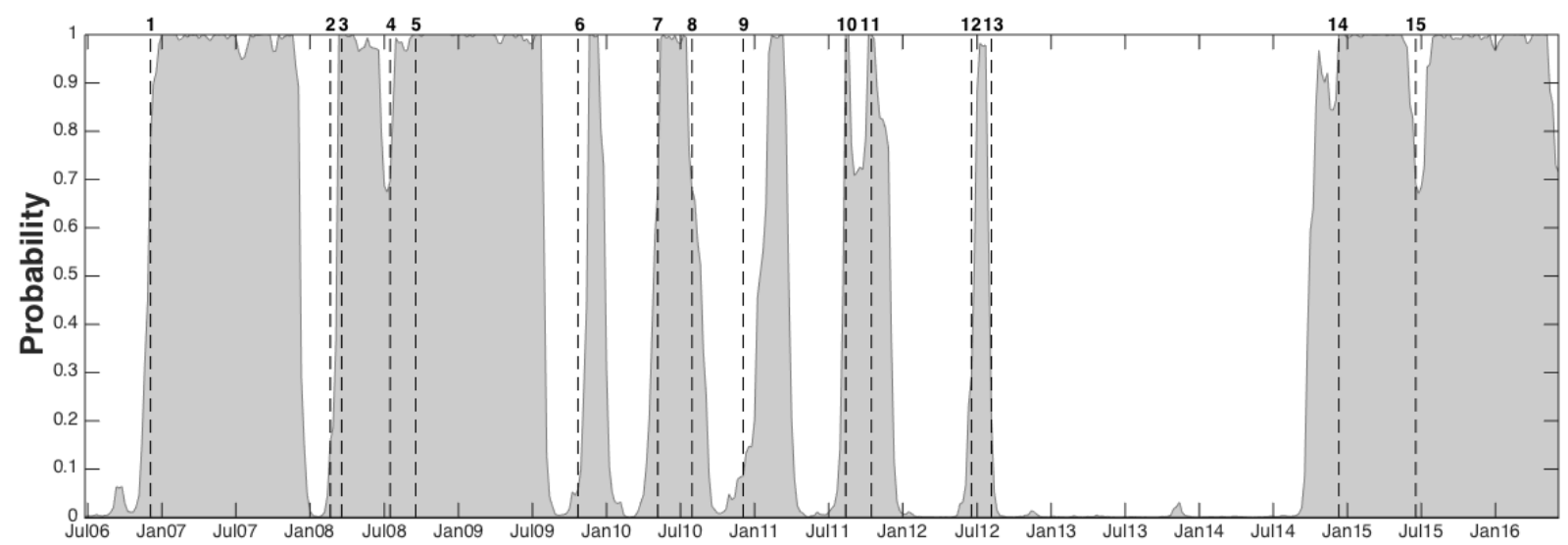

1: OPEC president expects oil output cuts; 2: Northern Rock in state ownership; 3: Bear Stearns takeover bid; 4: IndyMac Bank failure; 5: Lehman Brothers failure \& AIG rescue, OPEC production cutbacks; 6 : Greece's budget deficit expected to reach 12.5\% of GDP; 7: Greece bailout; 8: Dodd-Frank-Act; 9: Ireland bailout; 10: USA downgrading; 11: FED UMP announcement, ECB Covered Bond Purchase Programme; 12: Bank bailout Spain; 13: OMT London; 14: OPEC keeps production target despite oversupply; 15: OPEC Meeting

Note: Plot of the endogenously estimated smoothed probability of the high volatility state 2 , that is, the "turbulent state." Dashed lines correspond to selected events that are listed below the figure.

financial market turmoil. In detail, we observe two longer phases in state 2 which coincide with oil market specific events. The first is towards the start of the sample. There was a boom in oil prices related to expectations of OPEC supply cuts. It is important to bear in mind that also short-selling requires capital in the form of margins. The second phase is at the end of the sample and is in line with the plunge in oil prices from late 2014 onwards. This episode also raised more general concerns about the health of financial institutions with a large exposure to the oil sector (Domanski et al., 2015).

There area also several periods where the switch to state 2 is concurrent with general market turmoil, as during the global financial crisis. The probability peaks for some months when concerns about the solvency of several large banks (Northern Rock and Bear Stearns) intensified. With the first actual failure of a big bank (IndyMac), the subsequent bankruptcy of Lehman Brothers, and the rescue of AIG, the model enters a prolonged phase in state 2 that lasts until summer 2009. It also generates increased probabilities surrounding important events of the euro area crisis, such as the Greek bailout in summer 2010, potentially reflecting both the exposure of U.S. banks to the euro area and the presence of European banks on U.S. futures markets (CFTC, 2017b). Another short switch to state 2 occurs between the second half of 2011, which begins with the U.S. debt-ceiling crisis and the subsequent downgrading of the U.S. by Standard \& Poor's, as well as the return of the euro area crisis. All in all, this narrative indicates that our agnostic model seems to identify a high volatility state not only for periods of stress in the oil market but also for crisis times in other financial markets. To investigate this issue further, we later study the relation of the smoothed probability with other asset prices. 


\subsection{State-dependent Intermediary Pricing}

In the following we formally test our two main hypotheses by evaluating the estimated parameters of interest, and their statistical significance based on the Hessian. We also perform Likelihood Ratio tests to compare the baseline specification allowing for switches in all parameters with alternative models which restrict the parameters of interest to be time-invariant.

We start with the estimated instantaneous relations between variables in the tranquil state:

$$
A(1)=\bar{A}=\left(\begin{array}{rrl}
1 & 0 & 1.06^{* * *} \\
& & 0.22) \\
0 & 1 & \begin{array}{l}
1.52^{* * *} \\
(0.13)
\end{array} \\
& -1 & 0.56 \\
-1 & & 0.53)
\end{array}\right)
$$

The matrix corresponds to the one in the conceptual model so that we can interpret the estimated coefficients in the last column as the slope parameters of the demand curves of the three trader groups. Hedgers are ordered first, financial intermediaries second, and the group of others third. The values in parentheses show the standard errors. Asterisks indicate whether the parameters are different from zero $(*, * *, * * *$ correspond to significance at the $10 \%, 5 \%$, and $1 \%$ level, respectively). The estimated slopes for hedgers and financial intermediaries are highly statistically significant, with the latter demand curve being flatter. In tranquil times, intermediaries have the highest price elasticity and are the group most willing to take counterpositions. This ability shows how intermediaries facilitate hedging of producers and contribute to the functioning of the market. The slope parameter of others is not significant, potentially reflecting trader heterogeneity within this group.

To test Hypothesis 1, we evaluate $\mathcal{A}(2)$ which contains the changes in the slope coefficients when switching to state 2 :

$$
\mathcal{A}(2)=\left(\begin{array}{ccc}
0 & 0 & -0.31 \\
& & (0.28) \\
0 & 0 & -1.26^{* * *} \\
& & (0.14) \\
0 & 0 & 0.41 \\
& & (0.60)
\end{array}\right) .
$$

The only slope that changes significantly is the one for intermediaries. The change has the expected sign and is economically relevant. The demand curve steepens by more than $80 \%$. Adding $\bar{A}$ and $\mathcal{A}(2)$ yields the slope coefficients in state 2 :

$$
A(2)=\bar{A}+\mathcal{A}(2)=\left(\begin{array}{rrr}
1 & 0 & 0.75 \\
0 & 1 & 0.26 \\
-1 & -1 & 0.96
\end{array}\right) \text {. }
$$

Comparing the slope for intermediaries directly across regimes shows that $a^{F}(1)=1.52>$ $0.26=a^{F}(2)$, or, equivalently, that $a^{F}(1)-a^{F}(2)=1.26>0$. As this difference is statistically different from zero the estimates suggest that intermediaries absorb trades of other market 
participants to a lesser extent during turbulent times. This result lends support to the prediction of the theoretical literature that intermediary asset pricing is state-dependent, and shows that the oil futures market is a typical asset market. Moreover, together with the smoothed state probabilities it suggests that this market is not only affected by own developments but also by financial turmoil originating in other markets where financial intermediaries are active as well. Brunnermeier and Pedersen (2009) refer to this phenomenon as "commonality of liquidity across assets" which results from the difficulty of large banks to raise capital during periods of stress. As a result, market liquidity as a whole can decrease and observed price volatility increases.

To further judge the economic significance of the change in the demand functions, we interpret the overall contemporaneous effects of net long demand shocks in both states. They take into account all instantaneous feedback among positions and prices and are given by

$$
A(1)^{-1}=\left(\begin{array}{rrr}
0.66 & -0.34 & -0.34 \\
-0.48 & 0.52 & -0.48 \\
0.32 & 0.32 & 0.32
\end{array}\right), \quad A(2)^{-1}=\left(\begin{array}{rrr}
0.62 & -0.38 & -0.38 \\
-0.13 & 0.87 & -0.13 \\
0.51 & 0.51 & 0.51
\end{array}\right)
$$

Each column shows the effects of a demand shock of a given trader group on the positions of hedgers and intermediaries, and on prices. Comparing the response of intermediaries' positions to demand shocks of the other two trader groups between state 1 and 2 shows that intermediaries absorb trades from other market participants to a lesser extent in the turbulent state. The respective value decreases in absolute terms from 0.48 to 0.13 . Instead, intermediaries are mostly trading for own reasons, as indicated by the increase from 0.52 to 0.87 of the effect of their own shocks on own positions.

The bottom rows show that regardless of which trader groups' demand is shifting, the price impact in a given regime is the same as it depends on all traders' demand curves (see last rows in (3) and (9)). Across regimes, however, the price impact increases strongly, by nearly $60 \%$. When interpreting this number, one has to bear in mind that the elements in $A(S)^{-1}$ are functions of all three estimated slopes in $A(S)$ and that some coefficients and their changes are not statistically significant. But when considering only the significant change in the coefficient for intermediaries, $a^{F}$, the price effect of demand shocks is 0.53 , which is virtually the same as when considering all changes in slopes. ${ }^{4}$ Hence, regardless of the precise computation, the price impact of any trade in the market increases by almost two thirds in state 2, and the results indicate that this is mostly due to a steeper demand curve of financial intermediaries.

To test Hypothesis 2, we turn to the estimated structural variances in state $1, \Lambda(1)$, and their switch to state $2, \Lambda(2)$ :

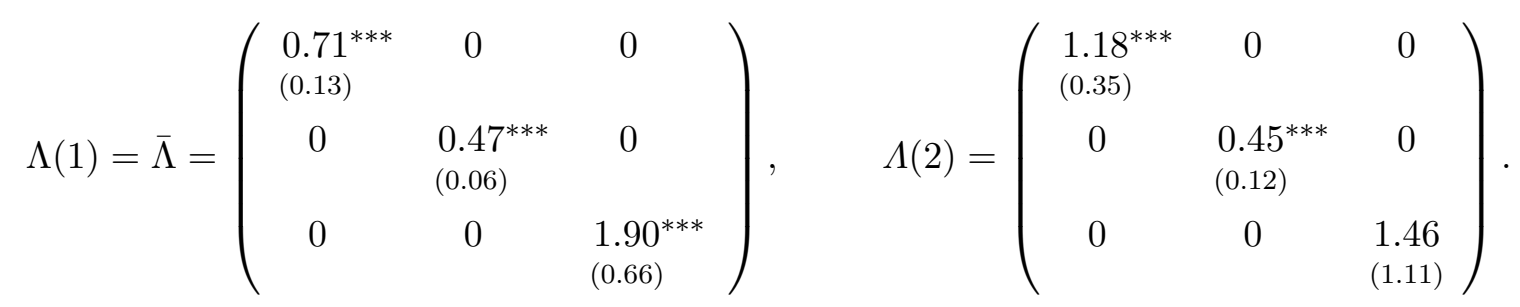

\footnotetext{
${ }^{4}$ In detail, the coefficients in the last row are given by $1 / \tilde{a}\left(S_{t}\right)$, where $\tilde{a}\left(S_{t}\right)=a^{H}\left(S_{t}\right)+a^{F}\left(S_{t}\right)+a^{O}\left(S_{t}\right)$. Hence, $1 / \tilde{a}(1)=0.32$ and $1 / \tilde{a}(2)=0.51$. If we only change $a^{F}\left(S_{t}\right)$ between states, that is $\tilde{a}\left(2^{*}\right)=a^{H}(1)+a^{F}(2)+a^{O}(1)$, then we obtain $1 / \tilde{a}\left(2^{*}\right)=0.53$.
} 
All variances in state 1 are statistically significant. If we interpret the coefficient for intermediaries as their exposure to idiosyncratic balance sheet shocks, then intermediaries have the smallest reaction to own shocks in state 1 . This finding is consistent with the idea that in normal times they can easily absorb ordinary balance sheet shocks. In state 2 , however, the volatility of demand shifts of intermediaries almost doubles from 0.47 to 0.92 . Importantly, the change $\lambda^{F}(2)-\lambda^{F}(1)=0.45>0$ is statistically significant at the one percent level. The estimates thus support Hypothesis 2 and suggest that during turbulent times the exposure of financial intermediaries to shocks hitting their balance sheets increases. Finally, the volatility of demand shocks of hedgers also changes significantly across regimes, being already relatively high in state 1. This finding suggests that producers and processors of oil have a large exposure to oil market specific shocks already during normal times, consistent with many items on their balance sheets being linked to the price of oil. This sensitivity increases further during episodes that contain large oil price swings.

Putting the results together, we calculate the overall impact of the different demand shocks on the endogenous variables. Using $\Lambda(2)=\bar{\Lambda}+\Lambda(2)$, they are given by

$$
A(1)^{-1} \Lambda(1)^{0.5}=\left(\begin{array}{rrr}
0.56 & -0.23 & -0.47 \\
-0.41 & 0.35 & -0.67 \\
0.27 & 0.22 & 0.44
\end{array}\right), \quad A(2)^{-1} \Lambda(2)^{0.5}=\left(\begin{array}{rrr}
0.85 & -0.36 & -0.70 \\
-0.18 & 0.83 & -0.24 \\
0.69 & 0.49 & 0.93
\end{array}\right) \text {. }
$$

The numbers resemble those in (9) but provide additional insights as they take into account the size of demand shifts. While in state 1 intermediaries' positions are more driven by trades of other market participants than by own needs, this drastically changes during state 2, where intermediaries change positions predominantly in response to own shocks. Moreover, when taking into account the larger variances in state 2 , the increase in the price impact of all demand shocks across regimes is even more pronounced. The price effects more than double in all cases.

Finally, we compare different model specifications through Likelihood Ratio tests as another means of analyzing the statistical properties of the main results. We compare the log-likelihood of the unrestricted baseline model, where all structural parameters are allowed to change across regimes, to three alternative restricted model variants, where some parameters are assumed to be time-invariant. We set either $\alpha^{F}(2)=0$ (see 5 ), $\ell^{F}(2)=0$ (see 6), or impose both restrictions simultaneously, that is, $\alpha^{F}(2)=\ell^{F}(2)=0$. Table 2 shows that in all three cases the $p$-values of the tests are essentially zero, clearly rejecting the restrictions. We conclude that a model which allows for fully state-dependent trading behavior of intermediaries is favored by the data.

Table 2: Likelihood Ratio Tests of Restrictions for the MSH-SVAR Model

\begin{tabular}{ccc}
\multicolumn{3}{c}{$H_{1}$ : baseline model specification } \\
\hline$H_{0}: \alpha^{F}(2)=0$ & $H_{0}: \ell^{F}(2)=0$ & $H_{0}: \alpha^{F}(2)=\ell^{F}(2)=0$ \\
$1.11 \mathrm{E}-16$ & $2.13 \mathrm{E}-04$ & 0 \\
\hline
\end{tabular}

Note: Likelihood Ratio tests comparing the baseline model specification (unrestricted model) with different alternative specifications in which parameters corresponding to financial intermediaries are set to zero (restricted model). Numbers represent $p$-values of the null hypothesis. 


\subsection{Impulse Responses and Forecast Error Variances}

The matrices discussed so far show differences in the impact effects of the shocks across states. We now present impulse responses to assess the dynamic effects. The bootstrapped confidence intervals also provide a further alternative of testing whether the effects are significantly different across regimes, both upon impact and subsequently. Figure 2 shows the cumulative responses in both states. ${ }^{5}$ The dashed line refers to the tranquil state and the solid line to the turbulent state. The shaded area displays $90 \%$ confidence intervals based on 1000 bootstrap replications. Overall, the figure corroborates the conclusions based on the impact effects. All responses are significantly different across regimes. In particular, the price effects of all three types of demand shocks are significantly larger in state 2. Moreover, we again find that financial intermediaries react stronger to their own shocks during turbulent times while absorbing less of the other traders' demand shocks. In contrast, hedgers react more to intermediaries' demand.

Figure 2: Cumulative Impulse Responses with $90 \%$ bootstrapped Confidence Intervals
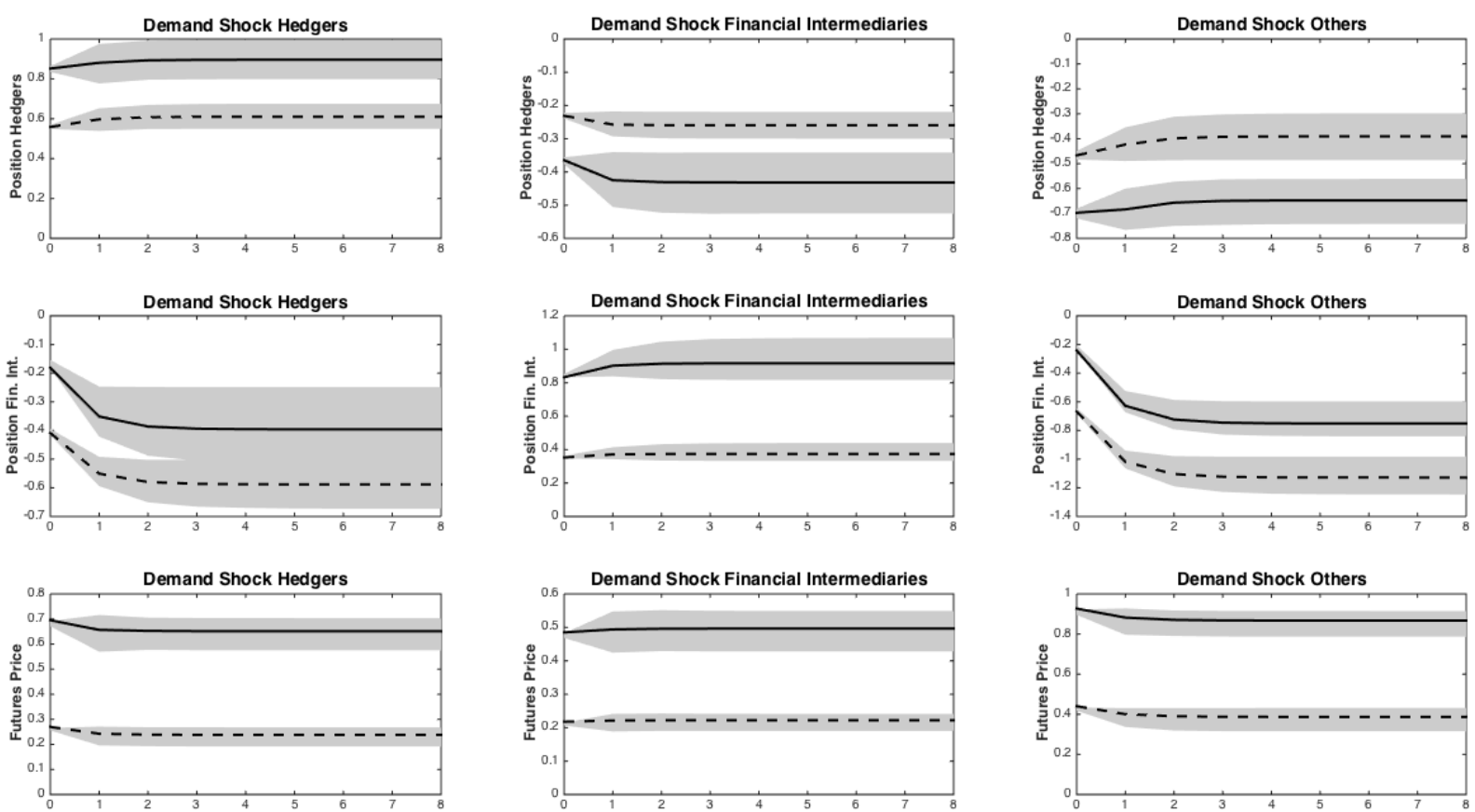

Note: Comparison of cumulative impulse responses of the three endogenous variables (in rows) to the three demand shocks (in columns) in state 1 (dashed line) and state 2 (solid line). Shaded areas represent $90 \%$ confidence intervals based on 1000 bootstrapped replications using a fixed design wild bootstrap. Vertical axes are in absolute changes in case of position variables and percentage changes in case of the futures price, horizontal axes are in weeks.

The figure also shows that the largest effects occur upon impact with only a limited role for the dynamics, in particular of prices. This observation is in line with asset prices and financial market participants responding instantaneously to each other, and has several implications. First, it suggests that the estimates and the statistical inference based on the impact matrices capture quantitatively most of the nonlinear effects of intermediary asset pricing. Second, it implies that other empirical approaches that are based on lead/lag relationships between variables for the identification of the impact of trading behavior on asset prices, or vice versa, are

\footnotetext{
5 The cumulative response for a given time horizon is the sum of all responses from the previous horizons until the current horizon. It therefore naturally stays persistent and is not expected to revert back to zero.
} 
likely to miss a relevant fraction of the overall effects. Finally, technically, it means that the underlying assumption of no regime change over the impulse horizon is not crucial as most of the difference between regimes is on impact. Moreover, this assumption seems plausible for the chosen horizon of eight weeks as Figure 1 indicates a high persistence of each state. In fact, the probability of staying in the current state is 0.96 for both states.

As a final means of quantifying the importance of state-dependencies we compute forecast error variance decompositions. They yield the average regime-specific contribution of the structural shocks to the variability of the endogenous variables. We focus on the contributions of the shocks upon impact which are similar to the decompositions for longer horizons. Table 3 shows that during tranquil times less than a fifth of the variability of intermediaries' positions is explained by own shocks. They mainly respond to demand shocks of hedgers and other traders. This is in stark contrast to the turbulent state, where nearly $90 \%$ of the variation in intermediaries' position is explained by own shocks. Each of the other two shocks contributes only about 5\%. Interestingly, the importance of intermediaries' demand shocks for price fluctuations remains constant across regimes at $15 \%$, despite a significant increase in the volatility of their demand shocks in state 2. This finding suggests that the main distinguishing feature of intermediaries relative to the other two trader groups is the significant decline in their price elasticity, which does not apply to the other two groups, rather than the increase in demand volatility in turbulent times, which is common to all three groups.

Table 3: Forecast Error Variance Decomposition

\begin{tabular}{lcccc}
\hline Variable & State & $\begin{array}{c}\text { Demand } \\
\text { Shock } \\
\text { Hedgers }\end{array}$ & $\begin{array}{c}\text { Demand } \\
\text { Shock } \\
\text { Fin.Int. }\end{array}$ & $\begin{array}{c}\text { Demand } \\
\text { Shock } \\
\text { Others }\end{array}$ \\
\hline Position Hedgers & 1 & 0.54 & 0.09 & 0.37 \\
Position Financial Intermediaries & 2 & 0.54 & 0.10 & 0.36 \\
Futures Price & 1 & 0.23 & 0.17 & 0.60 \\
& 2 & 0.04 & 0.88 & 0.07 \\
\hline
\end{tabular}

Note: Contribution of the three demand shocks to the forecast error variance of the endogenous variables upon impact in state 1 and state 2 . The results change only marginally for longer horizons given that there is not much persistence in the first-differenced variables.

\section{State Determination and Sensitivity Analysis}

In this section, we first estimate exogenous switching models with a single transition variable to assess the sensitivity of our results and to compare them with estimates from those popular alternative classes of nonlinear models. We then investigate whether combinations of variables can be associated with the regimes identified by the Markov switching model through logit regressions on the smoothed probabilities. The section concludes with a series of robustness tests of the Markov switching model. 


\subsection{Exogenous Switching Models}

Prominent examples of exogenous regime switching models are threshold and smooth transition SVARs. We estimate both types of models applying various transition variables, which reflect either general financial market or oil market conditions and are available at the weekly frequency. Following the literature we choose the VIX, the Baa-Aaa corporate bond spread, and the TED spread as measures of financial market conditions, and the realized volatility of the oil spot price as an oil market measure. ${ }^{6}$ Table 4 shows that all variables correlate reasonably and with the expected sign with the probability of the high volatility state, but are far from identical to it.

Table 4: Correlations

\begin{tabular}{lcccc}
\hline & VIX & Baa-Aaa spread & TED spread & Realized volatility \\
\hline State 2 prob. & 0.36 & 0.40 & 0.36 & 0.49 \\
\hline
\end{tabular}

Note: Correlations between smoothed state 2 probabilities and weekly financial variables. Variables are in levels. Sample period: June 27, 2006 to May 24, 2016. Number of observations: 518. See Table 8 in Appendix A for a description of the variables.

In the threshold SVAR, the exogenous switching occurs when the transition variable $s_{t}$ exceeds some certain threshold value at a specific observation date $t$. The threshold is typically chosen a priori and is often calibrated such that the model replicates some observed empirical pattern. We set it to be the $2 / 3$-quantile, $q_{s}(2 / 3)$, of the transition variable over the whole sample period:

$$
S_{t}= \begin{cases}1 & \text { if } s_{t} \leq q_{s}\left(\frac{2}{3}\right) \\ 2 & \text { if } s_{t}>q_{s}\left(\frac{2}{3}\right)\end{cases}
$$

This choice implies that the model dedicates $1 / 3$ of the sample period to the turbulent state, roughly consistent with the $32 \%$ of observations in state 2 in the baseline MSH-SVAR model. Changing the threshold value to the $3 / 4$-quantile affects the results only mildly.

The smooth transition specification follows (Kilian and Lütkepohl, 2017, Ch. 18) and calculates the exogenous switching probabilities based on the following logistic function:

$$
\begin{aligned}
& S_{t}(1)=\left(1+\exp \left\{-\gamma\left(s_{t}-\mu\right)\right\}\right)^{-1} \\
& S_{t}(2)=1-S_{t}(1),
\end{aligned}
$$

where $s_{t}$ denotes the transition variable, $\gamma>0$ is a slope parameter determining the smoothness of the transition, and $\mu$ is a location parameter defining the midpoint of the transition. To avoid scaling issues we standardize the exogenous transition variables which allows us to leave the slope parameter constant across specifications. We set it to $\gamma=25$, but our results are robust

${ }^{6}$ The VIX captures options-implied stock market volatility and is found to be linked to balance sheet constraints of intermediaries (Adrian and Shin, 2014). The Baa-Aaa spread is a commonly used indicator of credit spreads that signals default risk and possesses informational content for near-term economic growth (Gilchrist and Zakrajšek, 2012). The TED spread, defined as the interest difference between three-month euro interbank deposits (LIBOR) and three-month U.S. Treasury bills, is an indicator of funding constraints and has been shown to correlate negatively with liquidity in the currency market (Mancini et al., 2013). The weekly realized variance is computed following Bollerslev et al. (2009) and we take the square root of it. As this measure is relatively noisy, we use the 8-week moving average of it as transition variable. 
Figure 3: Exogenous Smooth Transition Probabilities of State 2
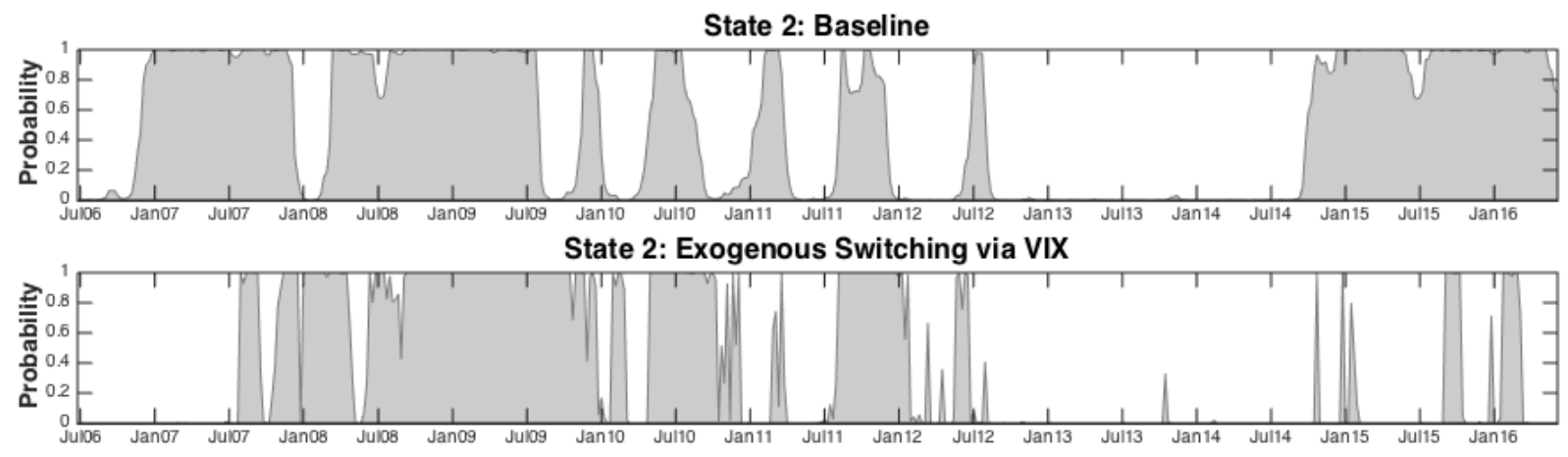

State 2: Exogenous Switching via Baa-Aaa Corporate Bond Spread

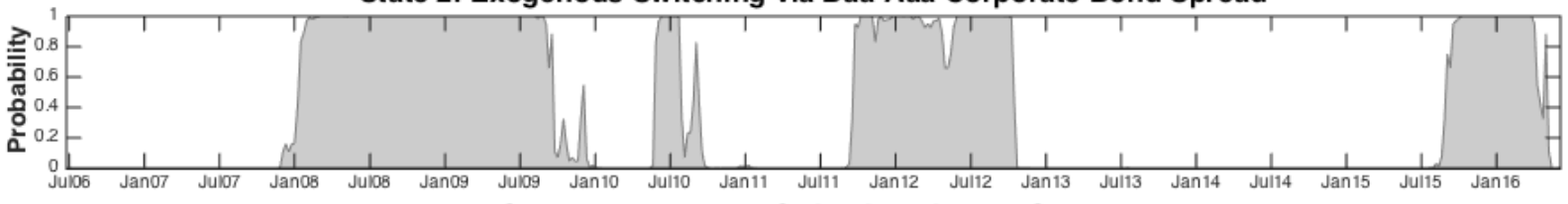

State 2: Exogenous Switching via TED Spread

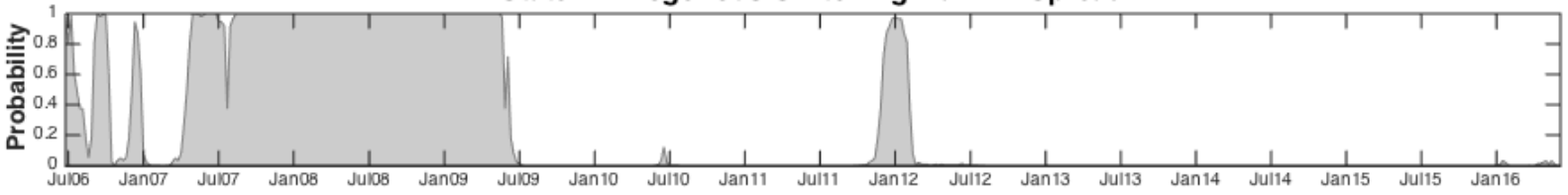

State 2: Exogenous Switching via Realized Volatility

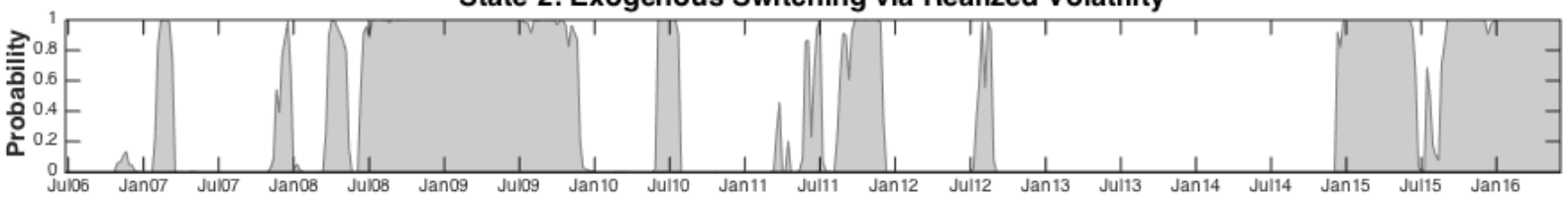

Note: Comparison of the smoothed probability of the high volatility state 2, that is, the "turbulent state," between the baseline model and a model with exogenous switching. In the baseline model the smoothed probabilities are endogenously estimated, while in the model with exogenous switching the transition between the two states is determined by a logistic function of a specific transition variable (the VIX, the Baa-Aaa corporate bond spread, the TED spread, or the realized volatility of the oil spot price).

to using smaller or larger values. For the location parameter, we use the mean of the transition variable over the sample period for simplicity.

Figure 3 displays the exogenously identified states from the smooth transition models. No single transition variable captures both the episodes of general market turmoil and the oilmarket-specific events that the MSH-SVAR model registers. When the VIX is used as a transition variable, the model partly misses oil-market-specific events, such as the strong oil price fluctuations in 2007 and towards the end of the sample. The Baa-Aaa spread based model, on the other hand, accounts for more of the later episode, but relatively late. Moreover, it seems to miss several of the spikes during the European debt crisis, probably reflecting that the transition variable refers to U.S. corporate bond yields. Similarly, the TED spread produces essentially transitions during the global financial crisis. Finally, the transition based on the realized oil price volatility tends to better capture both types of high volatility episodes, but partly neglects oil market events at the beginning of the sample and some switches during the European debt crisis. Moreover, the switches occur with some lag relative to the baseline model.

Table 5 contains the estimation results for both model types. Regardless of the specific transition variable, the estimated slopes of the demand curves are all highly significant in the tranquil state. In comparison to the baseline results, the slope for intermediaries is smaller 
in all cases but the change in the coefficient when switching to the turbulent state remains significant throughout. The variances of their demand shocks are all significant in the tranquil state, whereas the change in volatility to the turbulent state is only significant in some cases, and with the opposite sign. For all trader groups the volatility of demand shocks is considerably larger in the tranquil state, indicating that these models are less able to distinguish between different volatility regimes. The overall lower precision of the estimates is also reflected in a general loss of fit of these models relative to the Markov switching model. The latter yields higher log-likelihoods and is preferred according to both types of information criteria over any of the exogenous switching models (see second column). In summary, while the main results hold, the model fit deteriorates, the choice of the transition variable affects the results, and no single transition variable seems to recover the smoothed probabilities from the MSH-SVAR model. In the next section we therefore study whether a combination of variables can capture the smoothed probabilties.

\subsection{Regression Analysis of State Probabilities}

We relate the smoothed probability of state 2 of the MSH-SVAR model to a number of modelexternal variables through logit regressions. ${ }^{7}$ This analysis can add to the economic interpretation of the agnostically identified regimes and potentially allows inferring which other markets are relevant for the trading of intermediaries in the oil futures market.

Since the smoothed probability is a continuous measure, we transform it into a dichotomous variable by assigning 1 whenever it is above 0.5 , and 0 otherwise. Only $16 \%$ of the observations have a probability between 0.10 and 0.90 , supporting this transformation. As regressors, we include a constant and, as suggested by the MS process, one lag of the original state probability. Given the high autocorrelation of the smoothed probability, this lag transforms the model essentially into a specification in first differences. We therefore use first (log) differences of the other regressors as well, which also reduces the risk of spurious regression. The regressors are the four variables employed as exogenous transition variable, the log S\&P 500 index, the yield on ten-year U.S. Treasury bonds, a trade weighted U.S. Dollar index and the log oil spot price.

Table 6 shows the point estimates for the different variables, adding them one-by-one. Robust standard errors are in parentheses. The log odds for each variable has the expected sign and five out of the seven variables are significant. Increases in the VIX or the Baa-Aaa corporate bond spread signal higher uncertainty and reflect widening credit spreads, which are both signs of financial market stress. Increases in the $\mathrm{S} \& \mathrm{P} 500$, in the ten-year rate, and the oil spot price, on the other hand, lower the probability of state 2 . Lower equity or oil returns seem to have adverse effects on intermediaries' trading constraints. Together, the estimates support the conclusion from Figure 1 that the endogenously identified state 2 in the MSH-SVAR model reflects both oil and general financial market disturbances.

\footnotetext{
7 We choose a logit model for several reasons. First, standard OLS regressions seem inappropriate as the assumptions of linearity and homoskedasticity are violated. The smoothed probabilities show that many observations are close to 0 or 1 , with only few observations with values in between. We opt for a logit model over a probit model as the former has fatter tails and is less sensitive to outliers. Probit regressions yield similar results, with the coefficients being smaller in absolute value as it is usually the case. Standard diagnostics tests like the link test for model adequacy or the Hosmer-Lemeshow test as well as inspecting the receiver operating characteristic curve indicate that the model is well specified.
} 


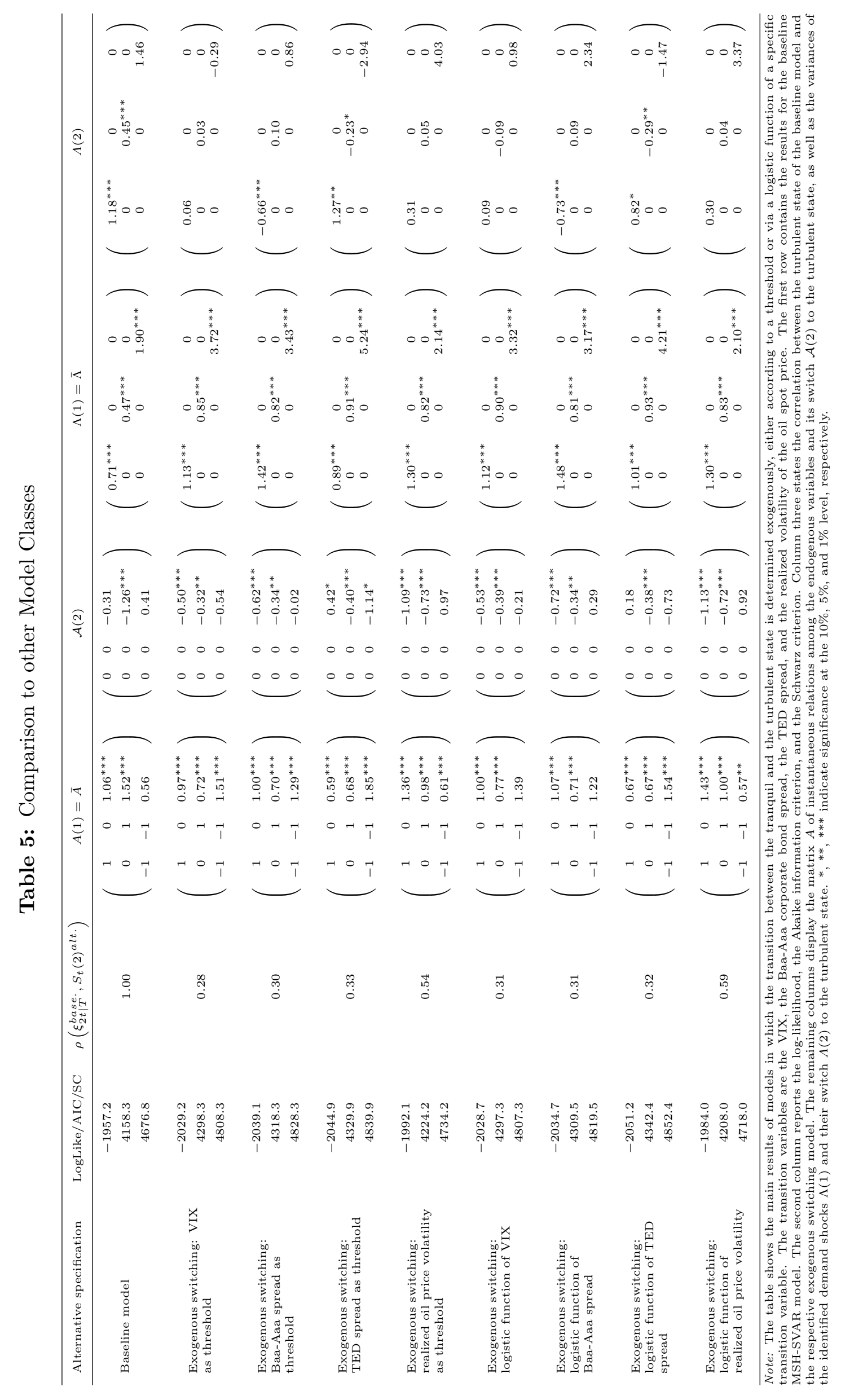


Table 6: Logit Regressions Baseline Results

\begin{tabular}{lcccccccc}
\hline Regressor & VIX & $\begin{array}{c}\text { Baa-Aaa } \\
\text { spread }\end{array}$ & $\begin{array}{c}\text { TED } \\
\text { spread }\end{array}$ & $\begin{array}{c}\text { Realized } \\
\text { volatility }\end{array}$ & $\begin{array}{c}\text { S\&P } \\
500\end{array}$ & $\begin{array}{c}\text { Ten-year } \\
\text { rate }\end{array}$ & $\begin{array}{c}\text { Exchange } \\
\text { rate }\end{array}$ & $\begin{array}{c}\text { Oil } \\
\text { price }\end{array}$ \\
\hline Coefficient & $0.19^{* * *}$ & $13.05^{* * *}$ & 0.95 & 11.34 & $-0.22^{*}$ & $-6.54^{* * *}$ & 0.46 & $-0.14^{* *}$ \\
Robust S.E. & $(0.07)$ & $(4.86)$ & $(1.46)$ & $(12.96)$ & $(0.11)$ & $(1.68)$ & $(0.30)$ & $(0.06)$ \\
\hline
\end{tabular}

Note: Logit models with dependent variable equal 1 if probability of state 2 of MSH-SVAR model $>0.5$, and 0 otherwise. Explanatory variables are in first differences and include a lag of the endogenous variable and a constant. Pseudo $R^{2}=0.90$ in all models. $*{ }^{* *},{ }^{* * *}$ indicate significance at the $10 \%, 5 \%$, and $1 \%$ level, respectively. Sample period: June 27,2006 to May 24, 2016, weekly frequency, 517 observations. See Table 8 in Appendix A for a description of the variables.

Table 7: Logit Regressions Extended Models

\begin{tabular}{lcccccccc}
\hline Variable & $(1)$ & $(2)$ & $(3)$ & $(4)$ & $(5)$ & $(6)$ & $(7)$ & $(8)$ \\
\hline VIX & $0.19^{* * *}$ & $0.17^{* *}$ & $0.19^{* *}$ & $0.18^{*}$ & $0.27^{*}$ & 0.24 & 0.23 & 0.23 \\
& $(0.07)$ & $(0.07)$ & $(0.08)$ & $(0.09)$ & $(0.16)$ & $(0.18)$ & $(0.16)$ & $(0.15)$ \\
Baa-Aaa spread & & $11.15^{* *}$ & $11.60^{* *}$ & $12.39^{* *}$ & $14.20^{* *}$ & $12.71^{* *}$ & $11.65^{* *}$ & $10.61^{*}$ \\
& & $(5.28)$ & $(5.16)$ & $(5.35)$ & $(5.73)$ & $(5.68)$ & $(5.93)$ & $(6.07)$ \\
TED spread & & & -1.84 & -1.83 & -2.17 & -2.47 & -1.56 & -1.25 \\
Realized volatility & & & $(1.67)$ & $(1.81)$ & $(1.64)$ & $(1.83)$ & $(2.39)$ & $(2.57)$ \\
& & & & 8.26 & 10.90 & 7.76 & 7.85 & 8.79 \\
S\&P 500 & & & $(10.78)$ & $(12.11)$ & $(11.58)$ & $(11.11)$ & $(10.61)$ \\
& & & & 0.15 & 0.25 & 0.29 & 0.32 \\
10y TB rate & & & & $(0.23)$ & $(0.21)$ & $(0.20)$ & $(0.19)$ \\
& & & & & & $-5.48^{* *}$ & $-6.05^{* * *}$ & $-5.70^{* * *}$ \\
Exchange rate & & & & & & $(2.30)$ & $(2.13)$ & $(2.07)$ \\
& & & & & & & 0.29 & 0.20 \\
Oil price & & & & & & & $(0.29)$ & $(0.30)$ \\
& & & & & & & -0.07 \\
Observations & 517 & 517 & 517 & 517 & 517 & 517 & 517 & 517 \\
Pseudo R & 0.90 & 0.90 & 0.90 & 0.90 & 0.91 & 0.91 & 0.91 & 0.91 \\
\hline
\end{tabular}

Note: Logit models with dependent variable equal 1 if probability of state 2 of MSH-SVAR model $\geq 0.5$, and 0 otherwise. Explanatory variables are in first differences and include a lag of the endogenous variable and a constant. Robust standard errors are in parentheses. ${ }^{*},{ }^{*},{ }^{* * *}$ indicate significance at the $10 \%, 5 \%$, and $1 \%$ level, respectively. Sample period: June 27, 2006 to May 24, 2016, weekly frequency. See Table 8 in Appendix A for a description of the variables.

In Table 7 we add the same variables sequentially to the model. Only two variables remain significant: the Baa-Aaa spread and the ten-year Treasury rate. The negative coefficient on the Treasury rate is consistent with "flight to quality" phenomena (Brunnermeier and Pedersen, 2009 ) in state 2 , induced by a commonality of liquidity across asset markets and resulting in declining yields. Both coefficients are also in line with risk premia and risk-free rates being important factors for the futures basis and hence for futures price dynamics (Acharya et al., 2013, Szymanowska et al., 2014).

\subsection{Sensitivity Analysis}

The section concludes with a number of robustness tests. First, we enlarge the baseline model by including another trader group, namely, the DCOT group of "Other Reportables." This group consists of reportable traders not classified as producers/processors/users, swap dealers, or money managers (see Appendix A). Second, as in Herwartz and Lütkepohl (2014), we allow for a third volatility state. Appendix B contains a figure with the smoothed probabilities for states 2 and 3. Third, we shorten the estimation period to June 12, 2007 until May 27, 2014 to exclude the large oil price swings at the beginning and end of the sample. Fourth, we allow for a more flexible specification with a switching intercept term. Fifth, we include all financial variables except of the oil spot price of Table 7 in first (log-)differences as exogenous control 
variables in the model. Sixth, we exclude all exogenous variables from the model. Seventh, we estimate a model with four lags. Eighth, we allow for predetermined exogenous variables. Ninth, instead of using the log-change in the oil futures price, we employ the change in the oil futures-spot basis as a third variable besides the two position variables.

Table 9 in Appendix B contains the key results of these alterations. They are qualitatively and mostly quantitatively similar to the baseline estimates, which are repeated in the first row for comparison. In all specifications the demand curve of financial intermediaries steepens significantly in the turbulent state, and the volatility of their own demand shocks is significantly larger. The endogenously identified states are similar across specifications and the correlation between the probability of state 2 in the baseline model and in alternative specifications is usually quite high (see second column). ${ }^{8}$ Overall, the main results appear to be robust to the various alterations of the model and the data.

\section{Conclusion}

Modern asset pricing theories state that financial intermediaries face numerous frictions through which they affect the performance of financial markets. One of them is that during volatile times their trading constraints become binding and their risk-bearing capacity shrinks. Intermediaries may then be less able to enter new trades and may have to unwind existing positions. Such occasionally binding constraints lay the theoretical foundation for nonlinearities in the asset pricing of intermediaries (Brunnermeier and Pedersen, 2009, He and Krishnamurthy, 2013).

This paper contributes to the literature by building a Markov switching in heteroskedasticity structural vector autoregressive (MSH-SVAR) model that tests for the presence of such nonlinearities in the oil futures market. The model contains two endogenously identified states, one corresponding to low and one to high volatility. The empirical results suggest two central nonlinearities. First, the downward-sloping demand curve of intermediaries steepens significantly in the high volatility regime. The lower price elasticity implies that intermediaries accommodate given hedging needs of producers, processors and consumers of oil to a lesser extent, and that the price effect of these demand shocks increases strongly. Second, the volatility of intermediaries' own demand shocks increases significantly during these episodes. This raises futures price volatility further.

These findings indicate the existence and empirical relevance of the theoretically predicted state-dependency of intermediary asset pricing. Quantitatively, the estimates suggest that the steepening of the demand curve is the more important nonlinearity, and the main distinguishing feature of intermediaries relative to other trader groups in the oil futures market. Open questions are whether these nonlinearities are also present at lower frequencies and whether they help to explain the typically higher volatility of oil prices at high(er) frequencies.

\footnotetext{
8 One exception is the model with the futures basis, which is more volatile than the futures price. Further, the more volatile states 2 and 3 of the three-state model depict similar periods as state 2 in the baseline model, and would thus be jointly correlated with that state.
} 


\section{References}

Acharya, V. V., Lochstoer, L. A., and Ramadorai, T. (2013). Limits to Arbitrage and Hedging: Evidence from Commodity Markets. Journal of Financial Economics, 109(2):441-465.

Adrian, T., Etula, E., and Muir, T. (2014). Financial Intermediaries and the Cross-Section of Asset Returns. The Journal of Finance, 69(6):2557-2596.

Adrian, T. and Shin, H. S. (2014). Procyclical Leverage and Value-at-Risk. Review of Financial Studies, 27(2):373-403.

Bacchiocchi, E. and Fanelli, L. (2015). Identification in Structural Vector Autoregressive Models with Structural Changes, with an Application to US Monetary Policy. Oxford Bulletin of Economics and Statistics, 77(6):761-779.

Bollerslev, T., Tauchen, G., and Zhou, H. (2009). Expected Stock Returns and Variance Risk Premia. Review of Financial Studies, 22(11):4463-4492.

Brunnermeier, M. K. and Pedersen, L. H. (2009). Market Liquidity and Funding Liquidity. Review of Financial Studies, 22(6):2201-2238.

CFTC (2017a). Disaggregated Explanatory Notes. URL: http://www.cftc.gov/MarketReports/ CommitmentsofTraders/DisaggregatedExplanatoryNotes/index.htm (01/30/2017).

CFTC (2017b). Provisionally Registered Swap Dealers. URL: http://www.cftc.gov/lawregula tion/doddfrankact/registerswapdealer (01/13/2017).

Cheng, I.-H., Kirilenko, A., and Xiong, W. (2015). Convective Risk Flows in Commodity Futures Markets. Review of Finance, 19(5):1733-1781.

Cheng, I.-H. and Xiong, W. (2014). The Financialization of Commodity Markets. Annual Review of Financial Economics, 6:419-441.

Domanski, D., Kearns, J., Lombardi, M., and Shin, H. S. (2015). Oil and Debt. BIS Quarterly Review, March 2015.

Etula, E. (2013). Broker-Dealer Risk Appetite and Commodity Returns. Journal of Financial Econometrics, 11(3):486-521.

Fattouh, B., Kilian, L., and Mahadeva, L. (2013). The Role of Speculation in Oil Markets: What Have We Learned So Far? The Energy Journal, 34(3).

Fostel, A. and Geanakoplos, J. (2008). Leverage Cycles and the Anxious Economy. American Economic Review, 98(4):1211-1244.

Garbade, K. D. and Silber, W. L. (1983). Price Movements and Price Discovery in Futures and Cash Markets. The Review of Economics and Statistics, 65(2):289-297.

Gilchrist, S. and Zakrajšsek, E. (2012). Credit Spreads and Business Cycle Fluctuations. American Economic Review, 102(4):1692-1720.

Hamilton, J. D. (1994). Time Series Analysis, volume 2. Princeton University Press.

Hamilton, J. D. and Wu, J. C. (2015). Effects of Index-Fund Investing on Commodity Futures Prices. International Economic Review, 56(1):187-205.

Hansen, B. E. (1992). The likelihood ratio test under nonstandard conditions: testing the markov switching model of gnp. Journal of applied Econometrics, 7(S1).

He, Z., Kelly, B., and Manela, A. (2016). Intermediary Asset Pricing: New Evidence from Many Asset Classes. NBER Working Paper No. 21920.

He, Z. and Krishnamurthy, A. (2013). Intermediary Asset Pricing. American Economic Review, 103(2):732-770. 
Henderson, B. J., Pearson, N. D., and Wang, L. (2015). New Evidence on the Financialization of Commodity Markets. Review of Financial Studies, 28(5):1285-1311.

Herwartz, H. and Lütkepohl, H. (2014). Structural Vector Autoregressions with Markov Switching: Combining Conventional with Statistical Identification of Shocks. Journal of Econometrics, 183(1):104-116.

Heumesser, C. and Staritz, C. (2013). Financialisation and the Microstructure of Commodity Markets - A Qualitative Investigation of Trading Strategies of Financial Investors and Commercial Traders. Working Paper 44, Austrian Foundation for Development Research (ÖFSE).

Hirshleifer, D. (1990). Hedging Pressure and Futures Price Movements in a General Equilibrium Model. Econometrica, 58(2):411-428.

Kilian, L. and Lütkepohl, H. (2017). Structural Vector Autoregressive Analysis. Cambridge University Press, Cambridge.

Kilian, L. and Murphy, D. P. (2014). The Role of Inventories and Speculative Trading in the Global Market for Crude Oil. Journal of Applied Econometrics, 29(3):454-478.

Knittel, C. R. and Pindyck, R. S. (2016). The Simple Economics of Commodity Price Speculation. American Economic Journal: Macroeconomics, 8(2):85-110.

Krolzig, H.-M. (1997). Markov-Switching Vector Autoregressions. Modelling, Statistical Inference, and Application to Business Cycle Analysis, volume 454 of Lecture Notes in Economics and Mathematical Systems. Springer-Verlag, Berlin and Heidelberg.

Kyle, A. S. and Xiong, W. (2001). Contagion as a Wealth Effect. The Journal of Finance, 56(4):1401-1440.

Lanne, M., Lütkepohl, H., and Maciejowska, K. (2010). Structural Vector Autoregressions with Markov Switching. Journal of Economic Dynamics and Control, 34(2):121-131.

Lütkepohl, H. (2005). New Introduction to Multiple Time Series Analysis. Springer Verlag, Berlin and Heidelberg.

Mancini, L., Ranaldo, A., and Wrampelmeyer, J. (2013). Liquidity in the Foreign Exchange Market: Measurement, Commonality, and Risk Premiums. The Journal of Finance, 68(5):18051841.

Podstawski, M. and Velinov, A. (2016). The State Dependent Impact of Bank Exposure on Sovereign Risk. DIW Berlin Discussion Paper No. 1550.

Psaradakis, Z. and Spagnolo, N. (2006). Joint determination of the state dimension and autoregressive order for models with markov regime switching. Journal of Time Series Analysis, 27(5):753-766.

Rigobon, R. (2003). Identification through heteroskedasticity. The Review of Economics and Statistics, 85(4):777-792.

Shleifer, A. and Summers, L. H. (1990). The Noise Trader Approach to Finance. The Journal of Economic Perspectives, 4(2):19-33.

Shleifer, A. and Vishny, R. W. (1997). The Limits of Arbitrage. The Journal of Finance, $52(1): 35-55$.

Sockin, M. and Xiong, W. (2015). Informational Frictions and Commodity Markets. The Journal of Finance, 70(5):2063-2098.

Szymanowska, M., Roon, F., Nijman, T., and Goorbergh, R. (2014). An Anatomy of Commodity Futures Risk Premia. The Journal of Finance, 69(1):453-482.

\section{A Data Appendix}


Table 8: Definition of Variables

\begin{tabular}{|c|c|}
\hline Variable & Definition and Source \\
\hline $\begin{array}{l}\text { Position } \\
\text { Hedgers }\end{array}$ & $\begin{array}{l}\text { Net long position of the trader group "Producer/Merchant/Processor/User" in light sweet } \\
\text { crude oil traded at the New York Mercantile Exchange. Standardized first absolute differen- } \\
\text { ces. U.S. Commodity Futures Trading Commission (CFTC), Disaggregated Commitments of } \\
\text { Traders (DCOT) Report. }\end{array}$ \\
\hline $\begin{array}{l}\text { Position } \\
\text { Financial In- } \\
\text { termediaries }\end{array}$ & $\begin{array}{l}\text { Net long position of the trader group "Swap Dealer" in light sweet crude oil traded at the New } \\
\text { York Mercantile Exchange. Standardized first absolute differences. U.S. Commodity Futures } \\
\text { Trading Commission (CFTC), Disaggregated Commitments of Traders (DCOT) Report. }\end{array}$ \\
\hline Futures Price & $\begin{array}{l}\text { New York Mercantile Exchange light crude oil continuous futures settlement price. Standar- } \\
\text { dized first log-differences. Code: NCLCS00. Datastream. }\end{array}$ \\
\hline $\begin{array}{l}\text { Initial Jobless } \\
\text { Claims }\end{array}$ & $\begin{array}{l}\text { Number Initial Claims, Weekly, Ending Saturday, Seasonally Adjusted. Standardized first } \\
\text { log-differences. Federal Reserve Economic Data, St. Louis Fed. Series code: ICSA. }\end{array}$ \\
\hline $\begin{array}{l}\text { Fed Total } \\
\text { Assets }\end{array}$ & $\begin{array}{l}\text { All Federal Reserve Banks Total Assets, Millions of Dollars, Weekly, as of Wednesday, Not } \\
\text { Seasonally Adjusted. Standardized first log-differences. Federal Reserve Economic Data, St. } \\
\text { Louis Fed. Series code: WALCL. }\end{array}$ \\
\hline $\begin{array}{l}\text { U.S. Macroe- } \\
\text { conomic } \\
\text { Surprise } \\
\text { Indicators }\end{array}$ & $\begin{array}{l}\text { Difference between actual release and the median forecast estimate of economists surveyed } \\
\text { by Bloomberg. Indicators: American Consumer Spending Growth Rates MoM SA (PCE } \\
\text { CRCH:IND), Average Hourly Earnings MoM\% SA (AHE MOM\%:IND), Average Hourly } \\
\text { Earnings YoY\% SA (AHE YOY\%:IND), Business Inventories MoM SA (MTIBCHNG:IND), } \\
\text { Capacity Utilization \% of Total Capacity (CPTICHNG:IND), Conference Board Leading Indi- } \\
\text { cators MoM (LEI CHNG:IND), Construction Spending Total MoM SA (CNSTTMOM:IND), } \\
\text { Core Producer Price Index (PPI XYOY:IND), CPI Urban Consumers Less Food \& Energy } \\
\text { YoY NSA (CPI XYOY:IND), CPI Urban Consumers MoM SA (CPI CHNG:IND), CPI Ur- } \\
\text { ban Consumers YoY NSA (CPI YOY:IND), Durable Goods New Orders Industries MoM } \\
\text { SA (DGNOCHNG:IND), GDP Chained 2009 Dollars QoQ SAAR (GDP CQOQ:IND), } \\
\text { Housing Starts/Permits (NHSPSTOT:IND), Industrial Production MoM 2007=100 SA (IP } \\
\text { CHNG:IND), Initial Jobless Claims SA (INJCJC:IND), Markit Manufacturing PMI SA (MP- } \\
\text { MIUSMA:IND), Markit Services PMI Business Activity SA (MPMIUSSA:IND), Nonfarm } \\
\text { Payrolls Total MoM SA (NFP TCH:IND), Personal Consumption Expenditure CPI YoY SA } \\
\text { (PCE CYOY:IND), Personal Income MoM SA (PITLCHNG:IND), PPI Final Demand MoM } \\
\text { SA (PCE CYOY:IND), PPI Finished Goods SA MoM\% (PPI CHNG:IND), Producer Price } \\
\text { Index - Finished Goods (PPI YOY:IND), Productivity Output Per Hour Nonfarm Business } \\
\text { Sector QoQ SA (PRODNFR:IND), Retail Sales (Less Auto and Gas Stations) SA MoM\% } \\
\text { Change (RSTAXAG\%:IND), Trade Balance of Goods and Services SA (USTBTOT:IND), } \\
\text { Unit Labor Costs Nonfarm Business Sector QoQ\% SAAR (COSTNFR\%:IND), University of } \\
\text { Michigan Consumer Confidence Indicator (CONSSENT:IND), US Government Budget Ba- } \\
\text { lance FED (FDDSSD:IND) }\end{array}$ \\
\hline
\end{tabular}

10y TB rate 10 Year U.S. Treasury Benchmark Bond Redemption Yield, Weekly, Ending Tuesday. First absolute differences. Code: USBDS10Y. Datastream.

Baa-Aaa $\quad$ Difference between Moody's Seasoned Baa Corporate Bond Yield (C), Percent, Weekly, Ending spread Tuesday, Not Seasonally Adjusted and Moody's Seasoned Aaa Corporate Bond Yield (C) Percent, Weekly, Ending Tuesday, Not Seasonally Adjusted. First absolute difference. Federal Reserve Economic Data, St. Louis Fed. Series codes: DBAA and DAAA, respectively.

Exchange $\quad$ Trade Weighted U.S. Dollar Index: Major Currencies, Index 27.06.2006 = 100, Weekly, Ending rate Tuesday. First log-differences. Federal Reserve Economic Data, St. Louis Fed. Series code: DTWEXM.

Oil price Crude Oil Prices: West Texas Intermediate (WTI) - Cushing, Oklahoma, Dollars per Barrel, Weekly, Ending Tuesday, End of Period. First log-differences. Federal Reserve Economic Data, St. Louis Fed. Series code: DCOILWTICO.

Realized Square root of the weekly realized variance of the oil spot price, which is given by $R V_{t}=$ volatility $\quad \sum_{j=1}^{n}\left(p_{t-1+\frac{j}{n}}-p_{t-1+\frac{j-1}{n}}\right)^{2}$, where $p_{t}$ denotes the logarithm of the oil spot price and $n$ is the number of trading days during week $t$. First absolute differences. Source of the oil price see above.

S\&P $500 \quad$ Standard \& Poor's 500 Stock Market Index, Weekly, Ending Tuesday. First log-differences (that is, the return). Yahoo Finance.

TED spread TED Spread, Weekly, Ending Tuesday, End of Period. First absolute difference. Federal Reserve Economic Data, St. Louis Fed. Series code: TEDRATE.

VIX CBOE Volatility Index: VIX, Weekly, Ending Tuesday, End of Period. First absolute difference. Federal Reserve Economic Data, St. Louis Fed. Series code: VIXCLS.

\section{Definitions of Trader Groups in DCOT Reports}

Below are the definitions of the four trader groups in the DCOT Reports as stated in CFTC (2017a). The fifth group of "Non-Reportables" is a residual component. 
Producer/Merchant/Processor/User: An entity that predominantly engages in the production, processing, packing or handling of a physical commodity and uses the futures markets to manage or hedge risks associated with those activities.

Swap Dealer: An entity that deals primarily in swaps for a commodity and uses the futures markets to manage or hedge the risk associated with those swaps transactions. The swap dealer's counterparties may be speculative traders, like hedge funds, or traditional commercial clients that are managing risk arising from their dealings in the physical commodity.

Money Manager: A registered commodity trading advisor (CTA); a registered commodity pool operator (CPO); or an unregistered fund identified by CFTC. These traders are engaged in managing and conducting organized futures trading on behalf of clients.

Other Reportables: Every other reportable trader that is not placed into one of the other three categories is placed into the "other reportables" category.

Non-Reportables: The remainder of total open interest in the specific futures market that is not accounted for by the other four categories of traders.

\section{B Sensitivity Analysis: Additional Figure and Table}

Figure 4: Smoothed Probability of the two volatile States in the Robustness Check

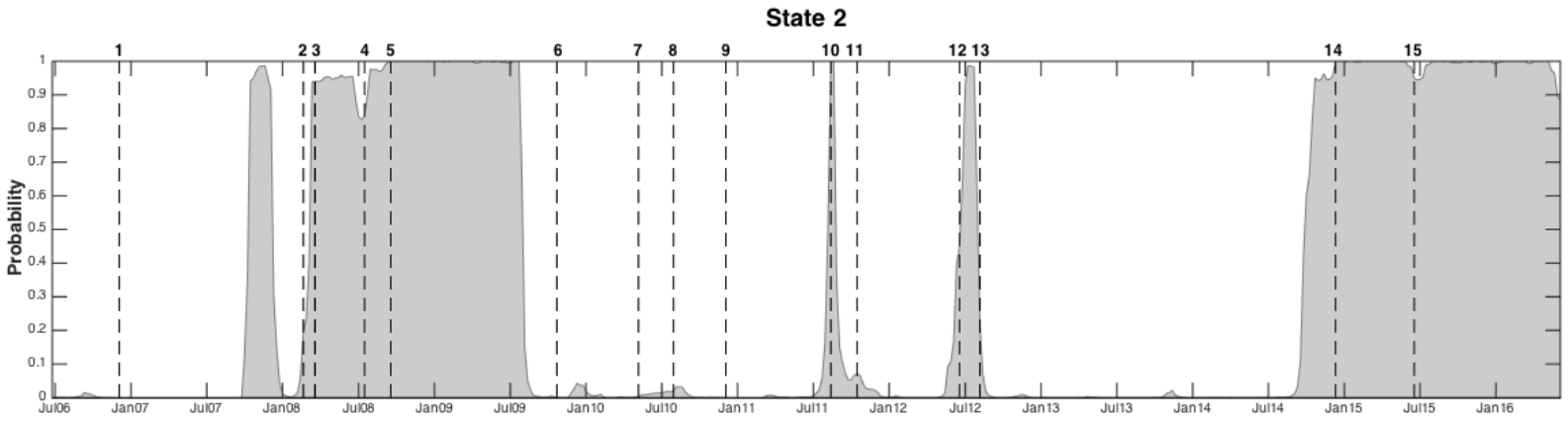

State 3

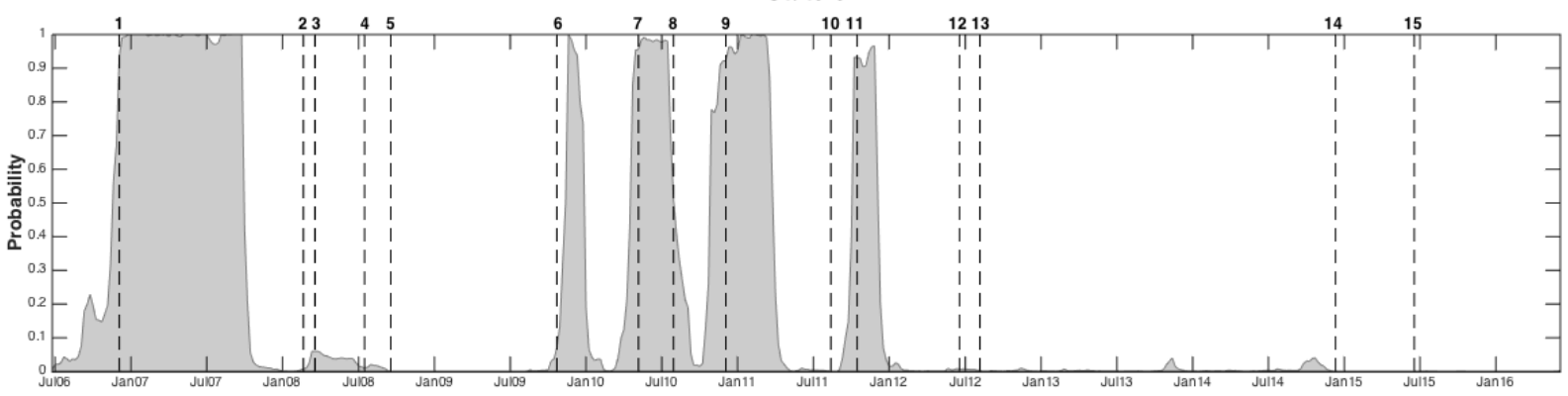

1: OPEC president expects oil output cuts; 2: Northern Rock in state ownership; 3: Bear Stearns takeover bid; 4: IndyMac Bank failure; 5: Lehman Brothers failure \& AIG rescue, OPEC production cutbacks; 6: Greece's budget deficit expected to reach $\sim 12.5 \%$ of GDP; 7: Greece bailout; 8: Dodd-Frank-Act; 9: Ireland bailout; 10: USA downgrading; 11: FED UMP announcement, ECB Ćovered Bond Purchase Programme; 12: Bank bailout Spain; 13: OMT London; 14: OPEC keeps production target despite oversupply; 15: OPEC Meeting

Note: Plot of the endogenously estimated smoothed probability of the two high volatility states, that is, the "turbulent states," in the robustness check of the baseline model with three different states. Dashed lines correspond to selected events that are listed below the figure. 


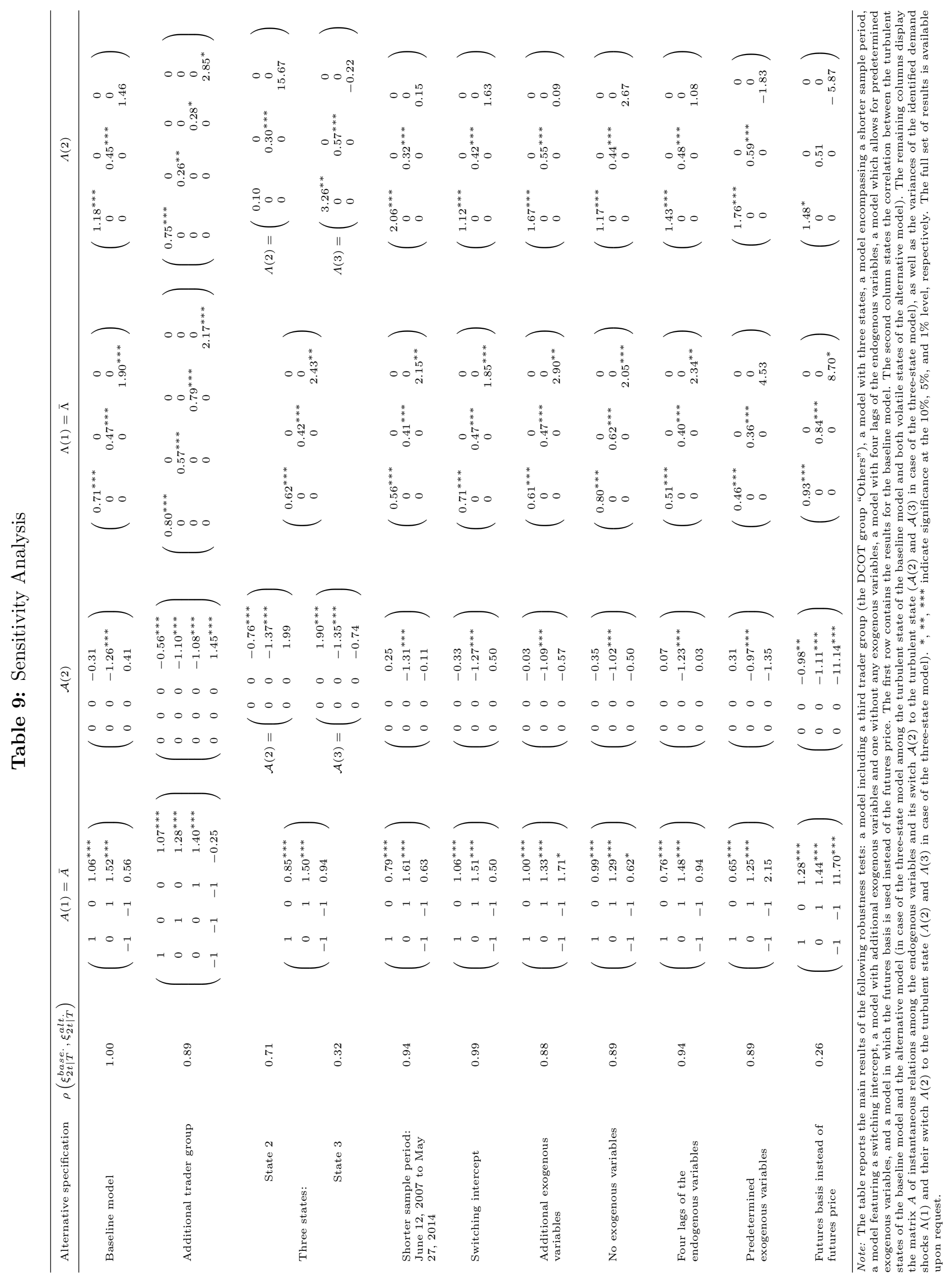

